\title{
The redox dependence of titanium isotope fractionation in synthetic Ti-rich lunar melts
}

\author{
Laura J. A. Rzehak ${ }^{1,2} \odot$. Sebastian Kommescher ${ }^{1,2} \cdot$ Florian Kurzweil $^{2} \cdot$ Peter Sprung $^{3} \cdot$ Felipe P. Leitzke $^{4}$. \\ Raúl O. C. Fonseca ${ }^{1,2}$
}

Received: 14 August 2020 / Accepted: 24 December 2020 / Published online: 28 February 2021

(c) The Author(s) 2021

\begin{abstract}
Equilibria between $\mathrm{Ti}$ oxides and silicate melt lead to $\mathrm{Ti}$ isotope fractionation in terrestrial samples, with isotopically light Ti oxides and isotopically heavy coexisting melt. However, while Ti is mostly tetravalent in terrestrial samples, around 10\% of the overall Ti is trivalent at $f \mathrm{O}_{2}$ relevant to lunar magmatism ( IW-1). The different valences of Ti in lunar samples, could additionally influence Ti stable isotope fractionation during petrogenesis of lunar basalts to an unknown extent. We performed an experimental approach using gas mixing furnaces to investigate the effect of Ti oxide formation at different $f \mathrm{O}_{2}$ on Ti stable isotope fractionation during mare basalt petrogenesis. Two identical bulk compositions were equilibrated simultaneously during each experiment to guarantee comparability. One experiment was investigated with the EPMA to characterize the petrology of experimental run products, whereas the second experiment was crushed, and fabricated phases (i.e., oxides, silicates and glass) were handpicked, separated and digested. An aliquot of each sample was mixed with a Ti double-spike, before Ti was separated from matrix and interfering elements using a modified HFSE chemistry. Our study shows $f \mathrm{O}_{2}$-dependent fractionation within seven samples from air to IW-1, especially $\Delta^{49} \mathrm{Ti}_{\text {armalcolite-melt }}$ and $\Delta^{49} \mathrm{Ti}_{\text {armalcolite-orthopyroxene }}$ become more fractionated from oxidized to reduced conditions $(-0.092 \pm 0.028--0.200 \pm 0.033 \%$ and $-0.089 \pm 0.027--0.250 \pm 0.049$ $\%$, respectively), whereas $\Delta^{49} \mathrm{Ti}_{\text {orthopyroxene-melt }}$ shows only a minor fractionation $(-0.002 \pm 0.017-0.050 \pm 0.025 \%$ ). The results of this study show that $\mathrm{Ti}$ isotope fractionation during mare basalt petrogenesis is expected to be redox dependent and mineral-melt fractionation as commonly determined for terrestrial $f_{2}$ may not be directly applied to a lunar setting. This is important for the evaluation of $\mathrm{Ti}$ isotope fractionation resulting from lunar magmatism, which takes place under more reducing conditions compared to the more oxidized terrestrial magmatism.
\end{abstract}

Keywords Titanium isotopes $\cdot$ Lunar magma ocean $\cdot$ Fractionation $\cdot$ Experiments $\cdot$ Ti oxides $\cdot$ Armalcolite

Communicated by Hans Keppler.

Supplementary Information The online version contains supplementary material available at https://doi.org/10.1007/s0041 0-020-01769-y.

Laura J. A. Rzehak

laura.rzehak@rub.de

Sebastian Kommescher

s.kommescher@uni-koeln.de

Florian Kurzweil

flokurzweil@ hotmail.de

Peter Sprung

peter.sprung@psi.ch

Felipe P. Leitzke

felipeplgeo@gmail.com

Raúl O. C. Fonseca

raul.fonseca@rub.de
1 Institut Für Geologie, Mineralogie Und Geophysik, Ruhr Universität Bochum, Universitätsstr. 150, 44780 Bochum, Germany

2 Institut Für Geologie Und Mineralogie, Universität Zu Köln, Zülpicher Str. 49a, 50674 Köln, Germany

3 Paul Scherrer Institut, Forschungsstrasse 111, 5232 Villigen PSI, Switzerland

4 Instituto de Geociências, Universidade do Rio Grande do Sul, Av. Bento Gonçalves 9500, Porto Alegre 91540-070, Brazil 


\section{Introduction}

Titanium is a refractory, lithophile and fluid-immobile element (Kessel et al. 2005; Palme and O'Neill 2014). Due to the absence of Ti-bearing phases in Earth's mantle, Ti behaves as an incompatible element during partial melting, and terrestrial basalts, like mid-ocean ridge and ocean island basalts have $\mathrm{TiO}_{2}$ contents ranging between ca. 1.5 wt.\% and 5 wt.\% (e.g.,Gale et al. 2013; Prytulak and Elliott 2007). Lunar basalts, however, can be highly enriched in $\mathrm{TiO}_{2}$, reaching levels up to $16 \mathrm{wt} . \% \mathrm{TiO}_{2}$ (Marvin and Walker 1978), which is thought to result from the partial melting of Fe-Ti-oxide-rich cumulates in the lunar interior (Ringwood and Kesson, 1976; Beard et al. 1998; Leitzke et al. 2016). In terrestrial settings, $\mathrm{Ti}$ is almost exclusively tetravalent, although some recent studies have reported isolated instances of trivalent $\mathrm{Ti}$ present in oxide inclusions of carmeltazite $\left(\mathrm{ZrAl}_{2} \mathrm{Ti}_{4} \mathrm{O}_{11}\right.$ - Griffin et al. 2018) and tistarite $\left(\mathrm{Ti}_{2} \mathrm{O}_{3}\right.$ - Griffin et al. 2016), found in terrestrial corundum. Titanium varies between an average IVfold coordination $\left({ }^{\left[{ }^{[V}\right]} \mathrm{Ti}\right.$ ) in pyroxenes to VI-fold coordination $\left({ }^{[\mathrm{VI}]} \mathrm{Ti}\right)$ in Ti oxides such as ilmenite and armalcolite, whereas in silicate glasses it exhibits an average V-fold coordination (Leitzke et al. 2018). Stable isotope theory predicts that ${ }^{[\mathrm{V}]} \mathrm{Ti}$ and ${ }^{[\mathrm{IV}]} \mathrm{Ti}$ form stiffer bonds than ${ }^{\left[{ }^{[\mathrm{V}]} \mathrm{Ti}\right.}$ (Schauble 2004), which is expected to lead to the preferential incorporation of lighter Ti-isotopes into VI-fold coordinated Ti oxides. Consistently, lower coordinated Ti in coexisting silicate melts is isotopically heavier (Farges et al. 1996; Millet et al. 2016; Mandl 2019; Kommescher et al. 2020). In contrast to Fe-Ti oxide minerals the fractional crystallization of silicate minerals like pyroxene, olivine or plagioclase causes limited, and so far, unresolvable Ti stable isotopic differences (Johnson et al. 2019), because $\mathrm{Ti}$ is broadly incompatible in these minerals so that any potential mass-dependent stable isotope fractionation is beyond our current ability to resolve. Therefore, the fractional crystallization of Ti-bearing oxides is assumed to be the main driving mechanism for the Ti stable isotope fractionation in magmatic samples (Millet et al. 2016; Deng et al. 2019).

The interpretation of Ti stable isotope fractionation in lunar samples is more complex because of the lower oxygen fugacities $\left(f \mathrm{O}_{2}\right)$ that characterize lunar magmas, which are typically below the $\mathrm{Fe}-\mathrm{FeO}$ reference redox equilibrium (IW; Myers and Eugster 1983). Such reducing conditions mean that a significant proportion of $\mathrm{Ti}^{3+}$ is present in basaltic melts (10-30 at. \% of total Ti, Leitzke et al. 2018; Simon and Sutton 2018). Changes in the redox state of a given element should affect its isotope fractionation during magmatic processes, as it can affect the bonding nature, bonding strength and spatial coordination of that element in various phases (Schauble 2004). In the final stages of lunar magma ocean (LMO) solidification, ilmenite-bearing cumulates (IBC; Warren 1985; Longhi 1992; Shearer et al. 2006; Gross and Joy 2016) that are isotopically light, and an isotopically heavy residual component that is enriched in incompatible elements such as Th, K, REE and P (i.e., KREEP-Warren 1989) crystallized (see Millet et al. 2016; Greber et al. 2017a, b; Kommescher et al. 2020). Later formed lunar mare basalts that are subdivided into low- and high-Ti basalts based on their $\mathrm{TiO}_{2}$ contents (Warren and Taylor 2014), show only small but still resolvable differences in their $\delta^{49} \mathrm{Ti}$. Low-Ti basalts have a mean $\delta^{49} \mathrm{Ti}(+0.01 \pm 0.047 \%$; Millet et al. 2016; Kommescher et al. 2020) that resembles that of the BSE $(+0.005 \pm 0.005 \%$, Millet et al. 2016), and chondritic values (Greber et al. 2017b; Deng et al. 2018), whereas high-Ti basalts show a broader range of $\delta^{49} \mathrm{Ti}$ (between $+0.009 \%$ and $+0.115 \%$; Millet et al. 2016; Kommescher et al. 2020). The higher average $\delta^{49} \mathrm{Ti}$ of lunar mare basalts compared to their terrestrial counterparts is thought to be related to the partial melting or the assimilation of IBC during lunar mantle petrogenesis (see Millet et al. 2016). Working from a larger sample set, Kommescher et al. (2020) noted that ilmenite-bearing high- and low-Ti basalts (Apollo 12 and 17) were systematically heavier than non-ilmenite bearing basalts, which was interpreted to be the result of lunar mantle source heterogeneity, both in respect to their mineral modal proportions (Sprung et al. 2013) and the prevalent $f \mathrm{O}_{2}$ (Fonseca et al. 2014) during partial melting of the lunar mantle. Moreover, Kommescher et al. (2020) have pointed out that at least some of the variability in the $\delta^{49} \mathrm{Ti}$ of lunar mare basalts could result from the fractional crystallization of Fe-Ti oxides, like ilmenite and armalcolite, during magmatic differentiation. At oxygen fugacities relevant for lunar conditions (between one to two orders of magnitude more reduced than the $\mathrm{Fe}-\mathrm{FeO}$ reference redox equilibrium or IW-1 to IW-2; Wadhwa 2008), high-Ti basalts might be reduced enough for an incorporation of up to $10 \% \mathrm{Ti}^{3+}$ relative to their bulk Ti contents (Krawczynski et al. 2009; Leitzke et al. 2018; Simon and Sutton 2018). A decoupling of $\mathrm{Ti}^{3+}$ from $\mathrm{Ti}^{4+}$ could result in redox dependent Ti stable isotopic differences in high-Ti basalts. A similar redox decoupling process is associated, for example, with the high $\delta^{56} \mathrm{Fe}$ of MORB samples compared to their mantle sources (Dauphas et al. 2014; Poitrasson et al. 2014; Sossi and Moynier 2017). Furthermore, this expectation seems to be supported by recent ab initio modelling by Wang et al. (2020), whose models suggest the presence of $\mathrm{Ti}^{3+}$ could result in significant $\mathrm{Ti}$ isotope fractionation during magmatic processes, and extend beyond $\mathrm{Fe}-\mathrm{Ti}$ oxide-melt equilibria to include equilibria between silicate minerals and silicate melts. Moreover, synthetic 
clinopyroxene produced from experimental high-Ti silicate melts contains a mixture of IV- and VI-fold coordinated $\mathrm{Ti}$, with an average of $45 \%$, and as much as $82 \%$ of ${ }^{[\mathrm{IV}]} \mathrm{Ti}^{4+}$ in pyroxene (Leitzke et al. 2018). Ab initio modelling carried out by Leitzke et al. (2018) suggests that such a high proportion of Ti in low (IV-fold) coordination is expected to favour a heavy $\mathrm{Ti}$ isotope composition for pyroxene, which could be extrapolated to other silicate phases.

In this study we experimentally assess the extent and magnitude of Ti stable isotope fractionation between silicate melt, armalcolite and orthopyroxene as a function of $f \mathrm{O}_{2}$. We have carried out seven experiments using compositions from the $\mathrm{CaO}-\mathrm{MgO}-\mathrm{Al}_{2} \mathrm{O}_{3}-\mathrm{SiO}_{2}+\mathrm{TiO}_{2}\left(\mathrm{CMAS}+\mathrm{TiO}_{2}\right)$ system that serve as analogues for high-Ti basalts. Compositions were chosen to reproduce equilibria between mineral phases found in lunar mare basalts and Ti-rich silicate melts. Oxygen fugacity conditions ranged from air to IW-1, reproducing highly oxidizing to highly reducing conditions of magma genesis and, therefore, terrestrial and lunar redox conditions. The different mineral phases in each experiment were separated and measured for their Ti isotope composition. The results were then fitted to a logistical function relating the $\mathrm{Ti}^{3+} /\left(\sum \mathrm{Ti}\right)$ of different phases in our experiments and the Ti isotope fractionation resulting from two phase equilibria $\left(\Delta^{49} \mathrm{Ti}_{\mathrm{A}-\mathrm{B}}\right)$, and subsequently compared with ab initio modelling, as well as Ti isotope data from natural lunar sample suites.

\section{Methods}

\section{Experimental protocol and sample preparation}

The starting composition of our experiments consisted of dried high purity major element oxide reagents (Alfa Aesar) mixed in the $\mathrm{CaO}-\mathrm{MgO}-\mathrm{Al}_{2} \mathrm{O}_{3}-\mathrm{SiO}_{2}$ (CMAS) system, to which ca. $20 \mathrm{wt} . \% \mathrm{TiO}_{2}$ were added (following Leitzke et al. 2016). To produce the starting material, dry oxide powders were ground together with acetone in an agate mortar $\left(\mathrm{CaCO}_{3}\right.$ was previously decarbonated overnight at $\left.900{ }^{\circ} \mathrm{C}\right)$. The mixture was dried, pressed into pellets, sintered at $900{ }^{\circ} \mathrm{C}$ and subsequently reground for further homogenization, and its composition is shown in Table 1. To avoid the loss of iron to the Pt wire and to be able to isolate the effect of $f \mathrm{O}_{2}$ on Ti stable isotope fractionation from potential interactions between $\mathrm{Fe}$ and $\mathrm{Ti}$, our starting composition was $\mathrm{FeO}$-free.

Experiments were performed in a $1 \mathrm{~atm}$ vertical gas mixing furnace at the University of Cologne (Germany) using the wire loop technique (Donaldson et al. 1975), and adhered closely to the experimental protocol described by Leitzke et al. (2016, 2017). For this purpose, each sample powder was mixed with polyethylene glycol and water to
Table 1 Composition of synthetic starting material used in this study

\begin{tabular}{lc}
\hline Composition & \multicolumn{1}{l}{$\begin{array}{l}\text { T5-20 } \\
\text { (in wt.\%) }\end{array}$} \\
\hline $\mathrm{SiO}_{2}$ & 43.06 \\
$\mathrm{TiO}_{2}$ & 22.06 \\
$\mathrm{Al}_{2} \mathrm{O}_{3}$ & 5.25 \\
$\mathrm{MgO}$ & 22.47 \\
$\mathrm{CaO}$ & 8.09 \\
Total & 100.93 \\
\hline
\end{tabular}

produce a slurry, which was then placed onto a metal loop and suspended inside the furnace at temperatures around $50-100{ }^{\circ} \mathrm{C}$ higher than the liquidus of the sample composition $\left(1400{ }^{\circ} \mathrm{C}\right)$. After a minimum-3-h period that ensured complete melting and homogenization, samples were cooled (cooling ramp of $0.04{ }^{\circ} \mathrm{C} / \mathrm{min}$ ) until the experiment reached its nominal target temperature $\left(1260{ }^{\circ} \mathrm{C}\right)$, where it remained another $72 \mathrm{~h}$ to ensure chemical equilibrium. This procedure was optimised to ensure that large enough $(>100 \mu \mathrm{m})$ crystals of orthopyroxene and armalcolite could grow in each experiment (see Hill et al. 2000; Leitzke et al. 2016). The temperature throughout the experiments was monitored using an external Type B thermocouple $\left(\mathrm{Pt}_{70} \mathrm{Rh}_{30}-\mathrm{Pt}_{94} \mathrm{Rh}_{6}\right)$. Quenching of the samples was performed in air, since $\mathrm{Pt}$ wire was used for all experiments. Oxygen fugacity was set by different $\mathrm{CO}-\mathrm{CO}_{2}$ gas mixtures and controlled using Tylan 2900 series mass flow controllers (see Supplementary Table 1). Furthermore, before and after each experiment, oxygen fugacity was monitored using a Y-stabilized zirconia oxygen sensor to verify how robustly the gas mixtures reproduced the desired $f \mathrm{O}_{2}$ of the experiment. Our experiments yielded crystals of armalcolite and orthopyroxene in equilibrium with glass (see Leitzke et al. 2016). For each experiment, two loops with the same composition were suspended in the furnace simultaneously. One of the loops was mounted in epoxy, polished and carbon coated for later EPMA and SEM analyses that aimed to identify the proportions of each mineral phase and major element compositions from the experiments. The second loop was gently crushed, and any minerals and glass contained within were handpicked and separated under reflected and transmitted light using a Zeiss stemi dv4 stereomicroscope with 32-times magnification. The glass was always transparent and showed characteristic conchoidal fracture, and any crystalline inclusions found within were immediately obvious. The orthopyroxenes were always white (iron-free) and showed a clear cleavage, making them easier to identify. The acicular armalcolite was black in all samples except in the experiment carried out in air, where it was colourless. Moreover, we selected only the mineral and glass separates devoid of obvious contaminants (i.e., inclusions and attached phases) for use in the Ti separation chemistry. This was especially important for 
the recovery of the relatively $\mathrm{TiO}_{2}$-poor orthopyroxene (ca. 1 wt. $\% \mathrm{TiO}_{2}$ ), which if contaminated by armalcolite (ca. $75 \mathrm{wt} . \%$ ), and to a lesser extent glass (ca. $15 \mathrm{wt} . \%$ ), would inevitably result in the adulteration of its Ti isotope composition. All phases that were separated with this procedure were subsequently digested, aliquoted, mixed with a Ti double spike and processed via column chemistry to purify $\mathrm{Ti}$ for MC-ICP-MS measurements.

\section{Chemical purification of titanium}

All acids used in this study $\left(\mathrm{HCl}, \mathrm{HF}\right.$ and $\mathrm{HNO}_{3}$ from EmsureV R, Merck) were distilled using Savillex DST1000 sub-boiling Teflon stills. All diluted acids were prepared with $18.2 \mathrm{M} \Omega / \mathrm{cm} \mathrm{H}_{2} \mathrm{O}$. All PFA vials were fluxed successively in reagent grade $3 \mathrm{M} \mathrm{HCl}, 5 \mathrm{M} \mathrm{HNO}_{3}$ and 18.2 $\mathrm{M} \Omega / \mathrm{cm} \mathrm{H}_{2} \mathrm{O}$ at $120^{\circ} \mathrm{C}$ for more than $48 \mathrm{~h}$ prior to use. The $\mathrm{H}_{2} \mathrm{O}_{2}$-bearing solutions for all columns were prepared shortly before each column chemistry to limit dissociation of $\mathrm{H}_{2} \mathrm{O}_{2}$. We followed the Ti separation procedure described by Kommescher et al. (2020), who themselves used a five step, heavily modified HFSE purification chemistry previously developed by Münker et al. (2001), Bast et al. (2015) and Tusch et al. (2019). The separation aimed on keeping Ti in solution during the purification procedure, and avoid a complete dry down and, therefore, precipitation of the samples, while maximizing the Ti chemistry yields.

Handpicked mineral and glass fractions recovered from each experiment were weighed and then digested in a 3:1 mixture of $14 \mathrm{M} \mathrm{HNO}_{3}$ and $24 \mathrm{M} \mathrm{HF}$ in pre-cleaned Savillex ${ }^{\circledR}$ PFA beakers. In addition to our samples, the Origins Lab Ti reference material (pure Ti metal rod-OL-Ti; Millet and Dauphas 2014; Millet et al. 2016), as well as a procedural blank, were individually processed in identical fashion. Furthermore, since we wanted to investigate the fractionation of $\mathrm{Ti}$ isotopes relative to our starting composition, our in-house glass reference material that was produced by fusing the bulk composition until homogeneous, was also processed during column chemistry.

After complete digestion was verified by visual inspection, aliquots were taken to determine the exact $\mathrm{Ti}$ concentration of each fraction using an iCap quadrupole ICP-MS. Afterwards, sample aliquots containing up to $30 \mu \mathrm{g}$ Ti were mixed with a Ti double spike in the ideal sample to spike proportion (sample:spike of 0.49:0.51—Rudge et al. 2009; Kommescher et al. 2020). We used a ${ }^{47} \mathrm{Ti}^{4}{ }^{49} \mathrm{Ti}$ double spike $(410.9 \pm 0.3 \mu \mathrm{g} / \mathrm{g})$ that was calibrated against the OL-Ti reference material (Kommescher et al. 2020). Samples were equilibrated overnight in a closed PFA beaker and subsequently evaporated at $75{ }^{\circ} \mathrm{C}$ on the hotplate. Dried samples were refluxed in $14 \mathrm{M} \mathrm{HNO}_{3}>>6 \mathrm{M} \mathrm{HCl}-0.06 \mathrm{M} \mathrm{HF}$ to prevent the formation of secondary fluorides from remaining HF. After drying samples at $75^{\circ} \mathrm{C}$, they were refluxed in $6 \mathrm{M} \mathrm{HCl}-0.06 \mathrm{M} \mathrm{HF}$ to convert the sample solution into chloride form and to dissolve nitrate precipitates. Samples were then dried at $75{ }^{\circ} \mathrm{C}$, laced with $1 \mathrm{~mL} 1.75 \mathrm{M} \mathrm{HCl}-2$ vol. $\% \mathrm{H}_{2} \mathrm{O}_{2}$ and centrifuged for ten minutes right before column chemistry.

All chromatographic separation resins were cleaned before and after each of the five separation steps. Each initial cleaning step was followed by equilibration with the acid used in the subsequent loading step to ensure that the ionic form of the resin was of the correct speciation relative to the mobile phase with which ion exchange takes place. Since our experimental samples were matrix-poor compared to natural samples, the chemical purification scheme described by Kommescher et al. (2020) had to be modified, as the lack of matrix elements caused an increased absorption of Ti, when samples were loaded in $1 \mathrm{M} \mathrm{HCl}-2 \mathrm{vol} . \% \mathrm{H}_{2} \mathrm{O}_{2}$ onto the cation resin AG50W-X8. Therefore, with $1 \mathrm{M} \mathrm{HCl}-2$ vol. $\% \mathrm{H}_{2} \mathrm{O}_{2}$ from the original elution scheme, no Ti was recovered after the first step. To test the efficiency of the column chemistry, initial yield tests with all three different mineral separates (armalcolite, orthopyroxene and glass), and two different acid strengths, were performed. Prior to separation and at each subsequent step of our yield test, a $10 \%$ aliquot was removed and doped with $0.025 \mu \mathrm{g}$ to serve as an independent reference during subsequent measurements at the Thermo Scientific iCap quadrupole ICP-MS. Absolute and relative yields of all purification steps could thus be calculated. Our results show that by using a higher acid strength, it is possible to quickly elute all Ti. Using $1.5 \mathrm{M} \mathrm{HCl}-2 \mathrm{vol} . \% \mathrm{H}_{2} \mathrm{O}_{2}$ resulted in a prolonged Ti elution compared to using $1.75 \mathrm{M} \mathrm{HCl}-2$ vol. $\% \mathrm{H}_{2} \mathrm{O}_{2}$, which achieved the fastest accumulation of our Ti yield (Fig. 1c, mean relative Ti yields with two different acid strengths on AG50W-X8; dotted lines show elution with $1.75 \mathrm{M} \mathrm{HCl}$ ). Furthermore, sample loss of up to $50 \%$ was noticeable during the first clean-up on AG1-X8 (Fig. 1a, cyan blue bars indicate the relative cumulative yield from each step). The first clean-up step is designed to remove $\mathrm{Cr}$ and $\mathrm{V}$, which were purposely not present in our experiments as they were not added to the starting compositions to avoid known isobaric interferences during analysis. Therefore, this step was skipped in our chemistry to maximize the Ti yields. Nevertheless, $\mathrm{Cr}$ and $\mathrm{V}$ contents were monitored to test for any potential contamination from the furnaces and reagents used in the experiments, and their concentrations were found to be below detection limit. The adapted chemistry was performed as described in the following (see also Table 3):

During the first step, the sample matrix was eluted with $6 \mathrm{M} \mathrm{HCl}$ and separated from the HFSE (and Mo and W) plus $\mathrm{Ti}$, which was eluted using $1.75 \mathrm{M} \mathrm{HCl}-2$ vol. $\% \mathrm{H}_{2} \mathrm{O}_{2}$ in a AG50W-X8 (200-400 mesh) cation exchange resin until the remaining drop of acid at the tip of the column was colourless (11 mL $1.75 \mathrm{M} \mathrm{HCl}$ during yield tests). The second 

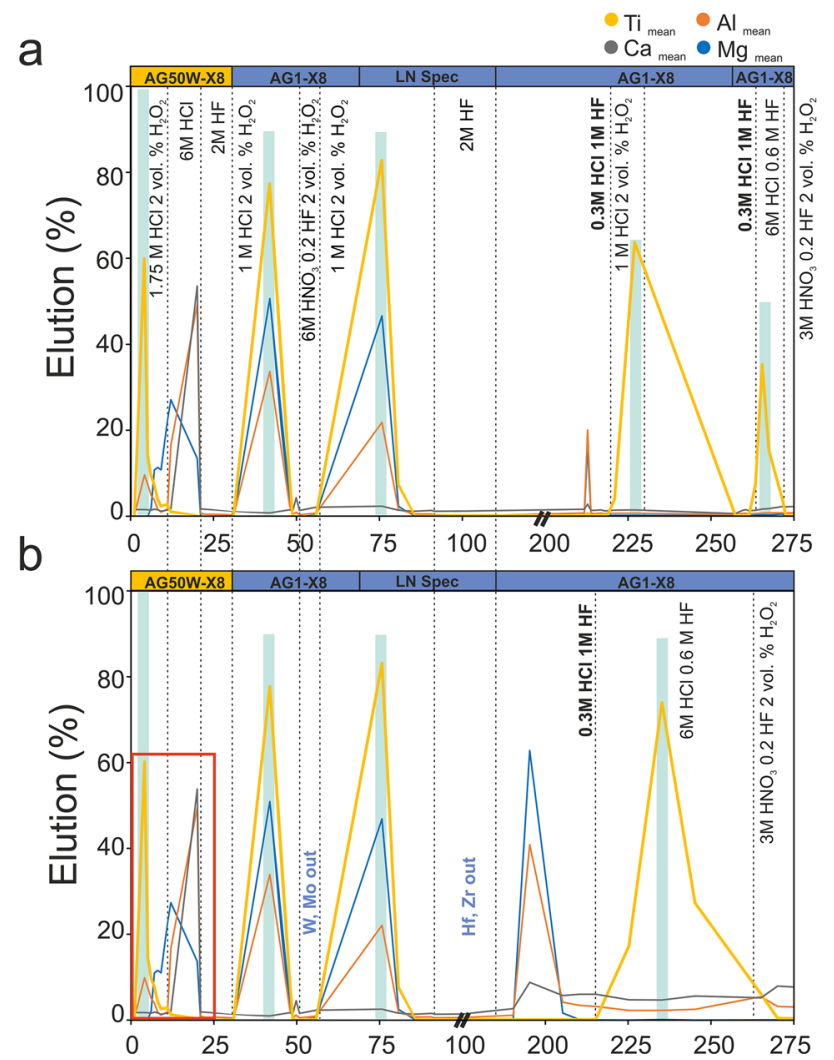

C

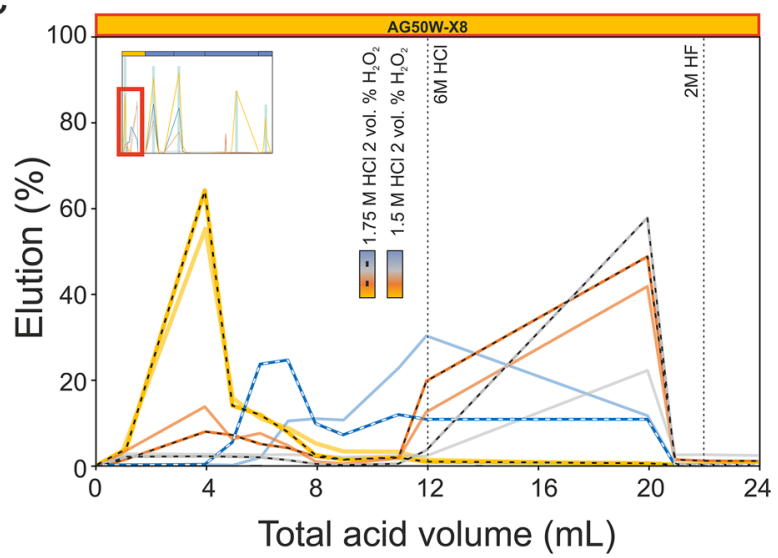

Fig. 1 Elution of Ti and matrix elements. To develop a new column chemistry for matrix-poor samples, we performed a column calibration for pure armalcolite, orthopyroxene and glass separates to test the elution of the elements that were used for our experiments. We took a $10 \%$ aliquot of each elution step, which was subsequently doped with an internal standard $(0.025 \mu \mathrm{g}$ In) to quantify yields after element concentration measurements at the Thermo Scientific iCap quadrupole ICP-MS. All elution lines for $\mathrm{Ti}, \mathrm{Mg}, \mathrm{Al}$ and $\mathrm{Ca}$ displayed here are average elution lines of all three phases. Cyan blue bars indicate the average relative cumulative yield of $\mathrm{Ti}$ after each respective column. Bold labels indicate the dilution of the samples with $18.2 \mathrm{M} \Omega / \mathrm{cm} \mathrm{H}_{2} \mathrm{O}$ and $24 \mathrm{M} \mathrm{HF}$ until present in $0.3 \mathrm{M} \mathrm{HCl}-1 \mathrm{M} \mathrm{HF}$ prior to loading them onto the columns. a Elution of $\mathrm{Ti}, \mathrm{Mg}, \mathrm{Al}$ and $\mathrm{Ca}$ in the 5 step chemistry. Due to the low acid strength of the first clean-up down to 50\% of $\mathrm{Ti}$ is lost after the clean-up steps as indicated by cyan blue bars. b The problem of sample loss was solved by performing the second clean-up only with a higher acid strength, which leads to higher yields in total (cyan blue bars for every respective column). Furthermore, the sample is matrix-free in the end. (c) Elution of $\mathrm{Ti}, \mathrm{Mg}, \mathrm{Al}$ and $\mathrm{Ca}$ with $1.5 \mathrm{M}$ (coloured lines) and $1.75 \mathrm{M}$ (dotted coloured lines) $\mathrm{HCl}$ during the first step of column chemistry (AG50W-X8). Overall, the higher acid strength of $1.75 \mathrm{M} \mathrm{HCl}$ during the first column leads to a faster elution of Ti separation step isolated $\mathrm{Ti}, \mathrm{Zr}$ and $\mathrm{Hf}(1 \mathrm{M} \mathrm{HCl}-2$ vol.\% $\mathrm{H}_{2} \mathrm{O}_{2}$ ) from $\mathrm{W}$ and $\mathrm{Mo}\left(6 \mathrm{M} \mathrm{HNO}_{3}-0.2 \mathrm{M} \mathrm{HF}-2\right.$ vol.\% $\mathrm{H}_{2} \mathrm{O}_{2}$ ) through a AG1-X8 (200-400 mesh) anion exchange resin. In a third step, $\mathrm{Ti}$ was separated from $\mathrm{Zr}$ and $\mathrm{Hf}$ in a column filled with Ln Spec resin, by loading and directly eluting Ti with $1 \mathrm{M} \mathrm{HCl}-2$ vol. $\% \mathrm{H}_{2} \mathrm{O}_{2}$, and subsequently eluting $\mathrm{Zr}$ and $\mathrm{Hf}$ using $2 \mathrm{M} \mathrm{HF}$. The fourth step of the Kommescher et al. (2020) protocol was skipped as described above; however, a final clean-up was important for the separation from residual matrix elements (Fig. $1 b-$ cyan blue bars indicate the relative cumulative yield from each step). Prior to this last step, samples were diluted with $18.2 \mathrm{M} \Omega$ / $\mathrm{cm} \mathrm{H}_{2} \mathrm{O}$ and $24 \mathrm{M} \mathrm{HF}$ until present in $0.3 \mathrm{M} \mathrm{HCl}-1 \mathrm{M} \mathrm{HF}$. Afterwards, the matrix was eluted using $0.3 \mathrm{M} \mathrm{HCl}-1 \mathrm{M}$ $\mathrm{HF}$, then Ti was eluted using $6 \mathrm{M} \mathrm{HCl}-0.06 \mathrm{M} \mathrm{HF}$ and $3 \mathrm{M}$ HNO3- $-2 \mathrm{M} \mathrm{HF}-2$ vol.\% $\mathrm{H}_{2} \mathrm{O}$ through the AG1-X8 resin to collect all $\mathrm{Ti}$. After the clean-up step, both the matrix and Ti cuts were dried down on a hotplate at $80{ }^{\circ} \mathrm{C}$. Nine parts of a $6 \mathrm{M} \mathrm{HNO}_{3}-0.2 \mathrm{M} \mathrm{HF}$ solution were mixed with one part $30 \% \mathrm{H}_{2} \mathrm{O}_{2}$ and every sample was laced with $2 \mathrm{~mL}$ of this solution to destroy organic components in the samples. After another sample dry down, all samples were taken up into $2 \mathrm{~mL}$ of the $0.3 \mathrm{M} \mathrm{HNO}_{3}-0.014 \mathrm{M} \mathrm{HF}$ running solution and transferred into $5 \mathrm{~mL}$ ICP-MS vessels. The mean relative Ti yield that resulted from our method was $\sim 90 \%$ in the yield test (see Supplementary Table 1and Fig. 1b). A Ti chemistry yield of $\sim 90 \%$ enabled us to measure samples that contain down to $6 \mu \mathrm{g} \mathrm{Ti}$, four times in 60 cycles at no loss of analytical precision compared to samples with higher Ti contents.

\section{Double spike MC—ICP-MS analysis}

A calibrated ${ }^{47} \mathrm{Ti}-{ }^{49} \mathrm{Ti}$ double spike was used for our analyses. The final concentration of the ${ }^{49 / 47} \mathrm{Ti}$ double spike is $410.9 \pm 0.3 \mu \mathrm{g} / \mathrm{g}$. The double spike was calibrated against OL-Ti as described by Kommescher et al. (2020).

Analyses of $\mathrm{Ti}$ stable isotope composition were performed on a Thermo Scientific Neptune MC-ICP-MS at the University of Cologne (Germany). Before each measurement session, detector gain and instrument baselines were determined. All measurements were run in high-resolution mode, to account for polyatomic interferences on ${ }^{46} \mathrm{Ti}$ and ${ }^{48} \mathrm{Ti}$, using a $\mathrm{Ni}$ sample cone and a $\mathrm{Ni}$ skimmer $\mathrm{H}$-cone. Typical resolving power (determined by $5-95 \%$ peak height) during each measurement was in the range of $\mathrm{R} \sim 10,000$. Lens setting and gas flows were tuned daily to maximize intensity and resolving power. Before and after each of the four measurement blocks of 60 cycles (integration time of $8.4 \mathrm{~s}$ ), a spiked OL-Ti solution was measured. Furthermore, each sample was bracketed by our synthetic reference material Col-Ti that was produced from a pure Ti metal rod from the same batch as that of reference standard OL-Ti (Millet 
and Dauphas, 2014), and is described in greater detail by Kommescher et al. (2020). This sample-standard bracketing was carried out to estimate the intermediate precision of our measurement, and to exercise further control on polyatomic interferences. Background measurements were performed for on-peak-zero corrections before and after each standardsample measurement block. For most analyses a 1 $\mu \mathrm{g} / \mathrm{mL}$ Ti solution was measured with a PFA nebulizer having an uptake rate of $125 \mu \mathrm{l} / \mathrm{min}$. This generated ${ }^{49} \mathrm{Ti},{ }^{48} \mathrm{Ti},{ }^{47} \mathrm{Ti}$ signal intensities of $2-3 \times 10^{-11} \mathrm{~A}(2-3 \mathrm{~V})$ using $10^{11}$ amplifiers. Background levels in a pure $0.3 \mathrm{M} \mathrm{HNO}_{3}-0.0014 \mathrm{M}$ HF solution were around $1-4 \times 10^{-15} \mathrm{~A}\left(1-410^{-4} \mathrm{~V}\right)$. Washout times were typically around $5 \mathrm{~min}$.

Data reduction was performed offline using a modified version of the Compston and Oversby (1969) algorithm, which allows us to estimate precision using counting statistics (Schoenberg et al. 2008; Kurzweil et al. 2018). Titanium isotope ratios are expressed in the $\delta$-notation (in per mil, $\%$ o) relative to OL-Ti following Millet and Dauphas (2014):

$\delta\left({ }^{49} \mathrm{Ti} /{ }^{47} \mathrm{Ti}\right)_{\mathrm{OL}-\mathrm{Ti}}=\left(\frac{{ }^{49} \mathrm{Ti} /{ }^{47} \mathrm{Ti}_{\text {sample }}}{{ }^{49} \mathrm{Ti} /{ }^{47} \mathrm{Ti}_{\mathrm{OL}-\mathrm{Ti}}}-1\right) \times 1000$

Our long-term reproducibility of OL-Ti is better than $0.035 \%$ ( 2 s.d.) after $\mathrm{n}=79$ measurements, which corresponds to a $95 \%$ confidence interval of $0.004 \%$ on $\delta^{49} \mathrm{Ti}$ (Fig. 2). The long-term reproducibility of our glass reference material is $0.020 \%$ ( 2 s.d.) after $n=13$ measurements, which corresponds to a $95 \%$ confidence interval of $0.006 \%$ on $\delta^{49} \mathrm{Ti}$. 95\% confidence interval is calculated including the student's $t$ test. All spike:sample ratios from this study are displayed in Supplementary Table 3.

\section{Results}

\section{Experimental run products}

All experiments yielded glass, orthopyroxene and armalcolite (Fig. 3). Mineral phases had crystal sizes exceeding hundreds of $\mu \mathrm{m}$ in length. The large crystal size can directly be related to the high bulk $\mathrm{TiO}_{2}$ content of the melt and is the result of decreased melt polymerization due to the addition of $\mathrm{TiO}_{2}$ to the melt (Neuville and Mysen 1996; Rai et al. 2019; also seen in Leitzke et al. 2016, 2017 for identical compositions).

Armalcolite typically shows acicular crystal habits, whereas orthopyroxene is predominantly prismatic (Fig. 3; see Leitzke et al. 2016). Minerals showed no compositional zonation, indicating equilibrium. Orthopyroxenes consist of pure enstatite $\mathrm{Mg}_{2} \mathrm{Si}_{2} \mathrm{O}_{6}$, whereas armalcolites are almost pure $\mathrm{MgTi}_{2} \mathrm{O}_{5}$ (i.e., Karrooite), comparable to $\mathrm{Mg}$-rich lunar armalcolites described in Haggerty (1973). Nevertheless,

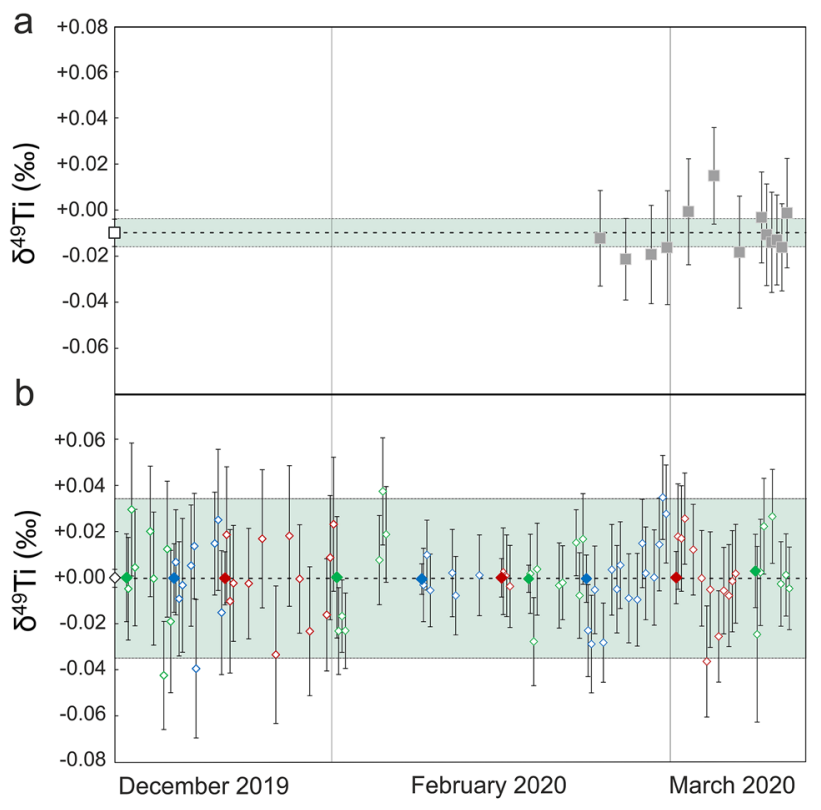

Fig. 2 Long-term reproducibility of glass reference material (top) and OL-Ti (below) over several months. Blue areas indicate the longterm $95 \%$ confidence interval. Colours of OL-Ti indicate different measurement sessions, whereas the large coloured dots represent the mean of the respective session. The large white dots are the overall means of the respective standard. OL-Ti was measured over several months from December 2019 to March 2020, whereas the more valuable synthetic glass reference material was measured only in the sessions, where synthetic samples were measured. Errors are stated as $95 \%$ confidence interval

EPMA measurements showed that cation deficiencies in armalcolite increased with decreasing $f_{2}$ of the experiments (see Supplementary Table 4), which can be explained by a small amount of $\mathrm{Ti}^{3+}$ present in the M2 site (Stanin and Taylor 1980) and was already described for a similar composition by Leitzke et al. (2016).

\section{Ti stable isotope composition of experimental run products}

Our results show that armalcolite has lighter Ti isotope compositions relative to the bulk composition of the experiment, and to the other coexistent phases (glass and orthopyroxene). Glass is isotopically lighter than orthopyroxene at low $f \mathrm{O}_{2}$, and both phases are isotopically heavier than the bulk composition (Table 2). Furthermore, the $\delta^{49} \mathrm{Ti}$ of all phases varies with $f \mathrm{O}_{2}$. Isotopic differences between phases become progressively larger the more reducing conditions become (Fig. 4 a, Table 2). The $\delta^{49} \mathrm{Ti}$ of armalcolite becomes gradually higher with decreasing $f \mathrm{O}_{2}$, increasing from $-0.056 \pm 0.019 \%$ in air to $-0.003 \pm 0.029 \%$ at IW- 1 , predominantly overlapping (within error) with the $\delta^{49} \mathrm{Ti}$ of the bulk composition $(-0.010 \pm 0.006 \% o)$. This overlap is 

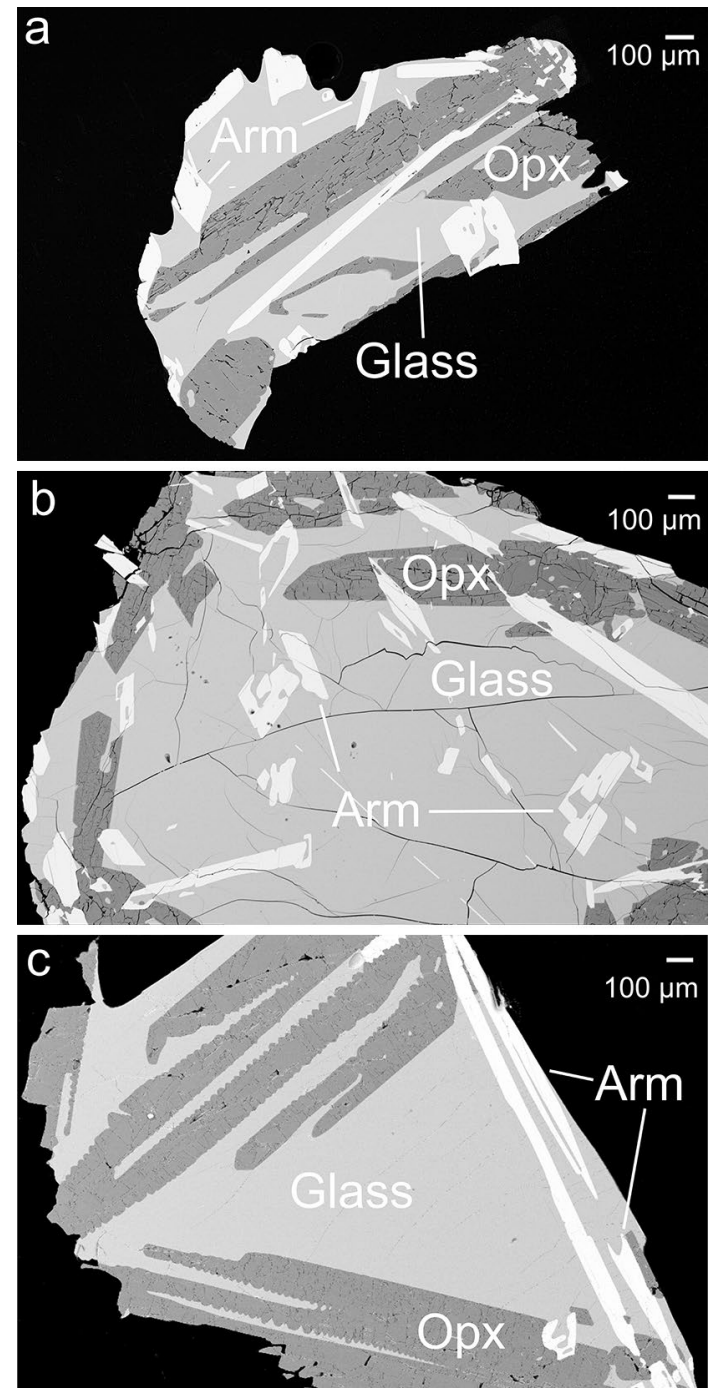

Fig. 3 Backscatter electron (BSE) images of typical run products. a T5-20 composition overview of a complete experimental run. b T5-20 composition with large armalcolite crystals. c T5-20 composition in a close-up with acicular armalcolite crystals

related to armalcolite having most of the bulk Ti content of the experiment, which means its $\delta^{49} \mathrm{Ti}$ is always close to that of the bulk composition of the experiment. Conversely, the $\delta^{49} \mathrm{Ti}$ of glass $(+0.035 \pm 0.009 \%$ at air to $+0.197 \pm 0.005$
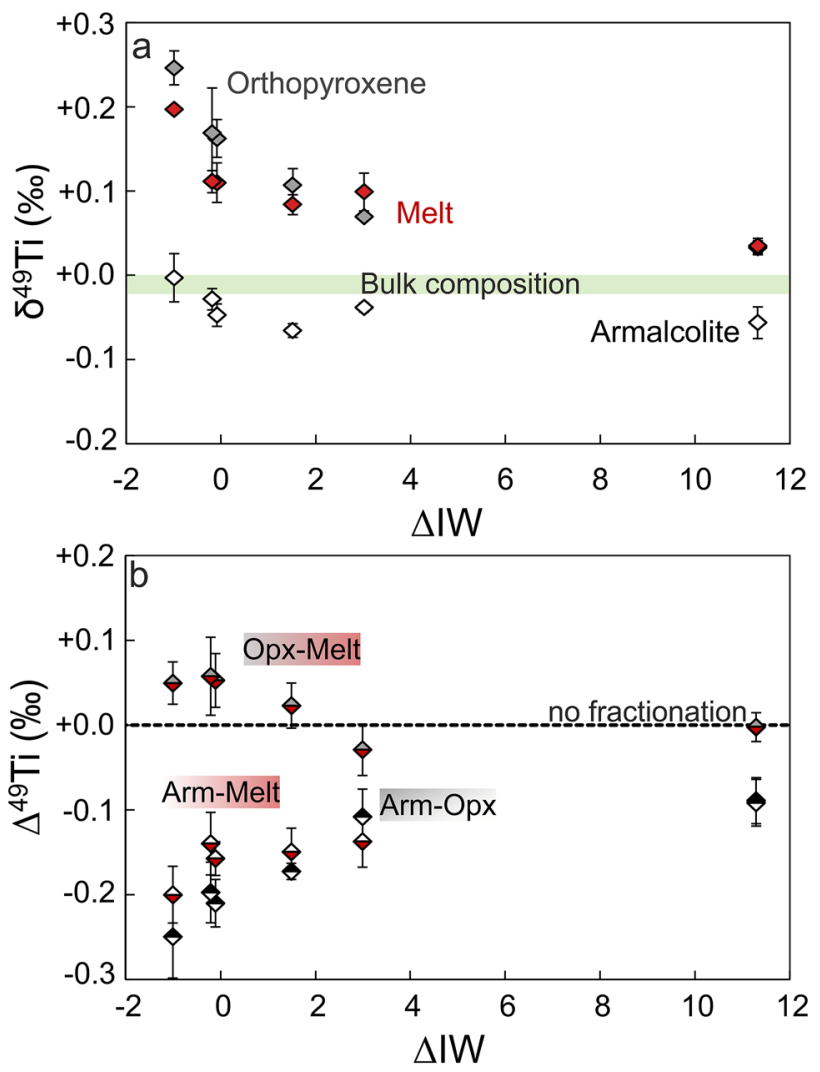

Fig. 4 Overview of $\delta^{49} \mathrm{Ti}$ and $\Delta^{49} \mathrm{Ti}$ compared to the $f \mathrm{O}_{2}$. a Titanium isotope composition of experimental run products (given as $\delta^{49} \mathrm{Ti}$ in $\%$ o ) as a function of $\mathrm{fO}_{2}$ relative to $\mathrm{Fe}-\mathrm{FeO}$ equilibrium $(\Delta \mathrm{IW})$. b Isotope fractionation $\left(\Delta^{49} \mathrm{Ti}\right)$ of orthopyroxene(opx)-melt, armalcolite(arm)-melt and armalcolite-orthopyroxene equilibria are shown relative to $\Delta \mathrm{IW}$

$\% o$ at IW-1), and orthopyroxene $(+0.033 \pm 0.009 \%$ to $+0.247 \pm 0.020 \%$ at IW-1) also increase with decreasing $\mathrm{fO}_{2}$, which is, at least, partly related to the distribution of $\mathrm{Ti}$ in the different phases present in the experiments. However, absolute changes in $\delta^{49} \mathrm{Ti}$ are much larger when orthopyroxene and silicate glass are compared to armalcolite. Therefore, a better measure of the effect that $f \mathrm{O}_{2}$ has on Ti isotope fractionation is to look at mineral-mineral and mineral-melt Ti isotope fractionation, as this parameter is independent of any Ti mass balance effect.
Table $2 \delta^{49} \mathrm{Ti}$ isotope composition and $95 \%$ c.i. in $\%$ of all synthetic phases at $1260{ }^{\circ} \mathrm{C}$ from this study

\begin{tabular}{|c|c|c|c|c|c|c|}
\hline \multirow[t]{2}{*}{$f \mathrm{O}_{2}$} & \multicolumn{2}{|c|}{ Orthopyroxene } & \multicolumn{2}{|c|}{ Armalcolite } & \multicolumn{2}{|l|}{ Glass } \\
\hline & $\overline{\delta^{49} \mathrm{Ti}}$ & $95 \%$ c.i & $\overline{\delta^{49} \mathrm{Ti}}$ & $95 \%$ c.i & $\overline{\delta^{49} \mathrm{Ti}}$ & $95 \%$ c.i \\
\hline Air & +0.033 & \pm 0.008 & -0.056 & \pm 0.019 & +0.035 & \pm 0.011 \\
\hline FMQ-0.5 & +0.070 & \pm 0.016 & -0.038 & \pm 0.016 & +0.099 & \pm 0.017 \\
\hline FMQ-2 & +0.107 & \pm 0.004 & -0.065 & \pm 0.005 & +0.084 & \pm 0.028 \\
\hline IW-0.1 & +0.163 & \pm 0.020 & -0.047 & \pm 0.008 & +0.110 & \pm 0.031 \\
\hline IW-0.2 & +0.169 & \pm 0.022 & -0.028 & \pm 0.013 & +0.112 & \pm 0.030 \\
\hline IW-1 & +0.247 & \pm 0.020 & -0.003 & \pm 0.029 & +0.197 & \pm 0.006 \\
\hline
\end{tabular}



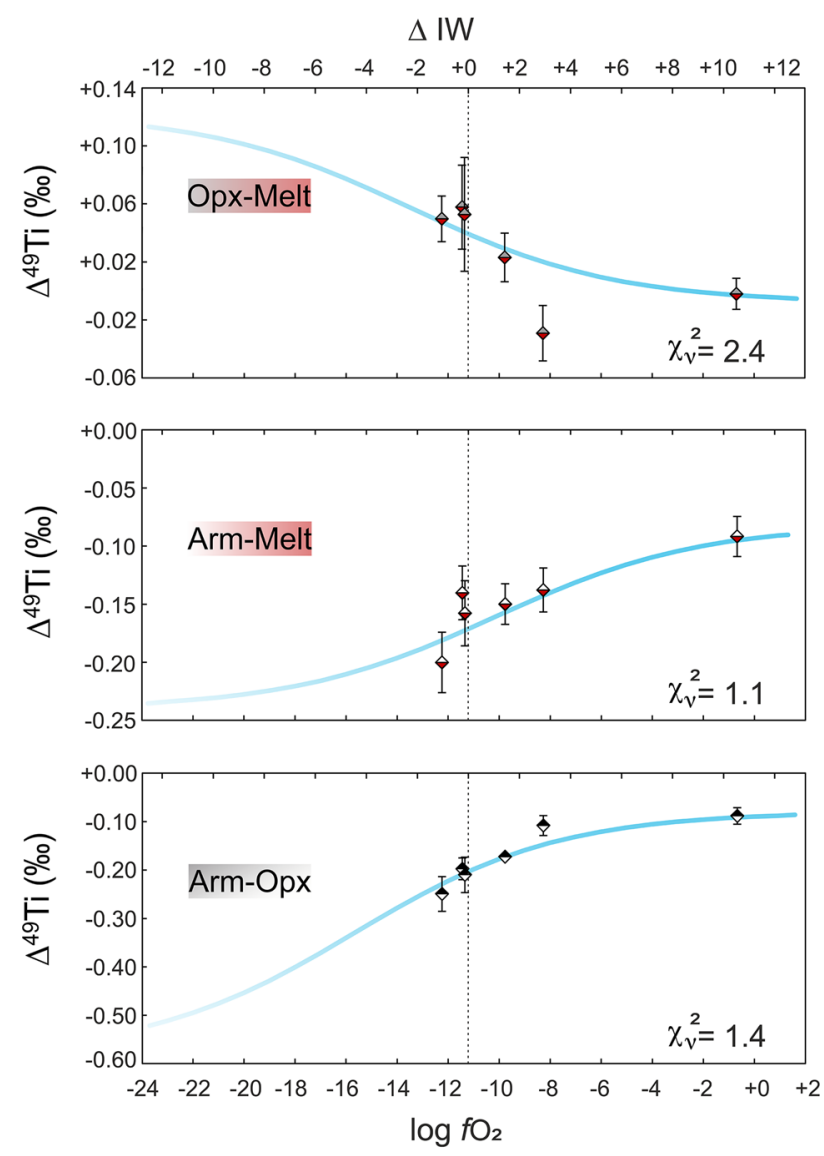

Fig. 5 Overview of $\Delta 49 \mathrm{Ti}_{\mathrm{A}-\mathrm{B}}$ compared to the absolute $f \mathrm{O}_{2}$ and $\Delta \mathrm{IW}$. Isotope fractionation $\left(\Delta 49 \mathrm{Ti}_{\mathrm{A}-\mathrm{B}}\right)$ of orthopyroxene (opx)-melt, armalcolite (arm)-melt and armalcolite-orthopyroxene equilibria is shown relative to $\log f \mathrm{O}_{2}$ and $\Delta \mathrm{IW}$. The thermodynamical fits represented by the blue line were calculated with Eq. 4 and the constants from Table 4 and show a clear redox-dependency of all equilibria

The Ti stable isotope fractionation $\left(\Delta^{49} \mathrm{Ti}_{\mathrm{A}-\mathrm{B}}=\delta^{49} \mathrm{Ti}_{\mathrm{A}}-\delta^{49} \mathrm{Ti}_{\mathrm{B}}\right)$ expressed in each phase is a function of the lever rule, enabling us to isolate what effect $f \mathrm{O}_{2}$ has on the fractionation of Ti isotopes between different phases in equilibrium (Fig. 4b).

Results show that the $\Delta^{49} \mathrm{Ti}_{\mathrm{A}-\mathrm{B}}$ for equilibria between armalcolite and other phases in the experiments (i.e., opx and melt) becomes more fractionated to lower values, at increasingly lower $f \mathrm{O}_{2}$ reaching -0.2 to $-0.25 \%$ for armalcolite-melt and armalcolite-opx equilibria, respectively, from a starting value of $\sim-0.1 \%$ in experiments carried out in air (see Table 3 and Supplementary Table 5). Interestingly, $\Delta^{49} \mathrm{Ti}_{\text {opx-melt }}$ also becomes more fractionated at lower $\mathrm{fO}_{2}$ but to more positive values, reaching a maximum of ca. $+0.04 \%$ at IW-1.

\section{Mass balance of experimental run products and their Ti isotope composition}

In all experiments, where both loops were recovered, we have carried out mass balances as a check for possible contamination during production of the different phase separates. First of all, we determined the modal abundance of each phase from SEM images of each experiment using ImageJ, and weighted them based on the density of each phases. Afterwards, we have determined the fraction of Ti present in each phase and multiplied it with the respective $\delta^{49} \mathrm{Ti}$ values. The result was then compared to the $\delta^{49} \mathrm{Ti}$ of our synthetic glass reference material. Mass balance calculations for almost all experiments are within 2 s.d. of the synthetic glass reference material $\left(\delta^{49} \mathrm{Ti}=-0.010 \pm 0.020\right.$ $\%$; see Supplementary Table 7). The only exception was the experiment at FMQ-0.5, where the bulk $\delta^{49} \mathrm{Ti}$ determined from the mass balance was $+0.040 \%$, which is $0.050 \%$ o higher than expected from our synthetic glass reference material. Since $\delta^{49} \mathrm{Ti}$ of orthopyroxene from this experiment is lower than the $\delta^{49} \mathrm{Ti}$ of the glass, it is likely that this orthopyroxene was contaminated by armalcolite driving its apparent $\delta^{49} \mathrm{Ti}$ to lower values and also to erroneous $\Delta^{49} \mathrm{Ti}$ values that are not in line with the redox dependent trends shown in Fig. 4 and Fig. 5. This can be confirmed by the $\chi^{2}$ values of our thermodynamic fit, where all $\Delta^{49} \mathrm{Ti}_{\mathrm{A}-\mathrm{B}}$ at FMQ- 0.5 associated with orthopyroxene leads to high $\chi^{2}$ values $(>3)$ in comparison to other $\chi^{2}$ values $(<1)$.

As shown by the mass balance carried out on the FMQ0.5 experiments, even slight variations resulting from either contamination during processing of the mineral separates, or from flawed estimates of mineral modal abundances in the experiments, have a large and obvious effect on the mass balance and $\Delta^{49} \mathrm{Ti}$ values. This indicates that all other
Table $3 \alpha$-values, $\Delta^{49} \mathrm{Ti}$ isotope composition and $95 \%$ c.i. in $\%$ of all synthetic phases at $1260{ }^{\circ} \mathrm{C}$ from this study

\begin{tabular}{|c|c|c|c|c|c|c|c|c|c|}
\hline \multirow[t]{2}{*}{$f \mathrm{O}_{2}$} & \multicolumn{2}{|c|}{ Arm-melt } & \multirow[t]{2}{*}{$\alpha$} & \multicolumn{2}{|l|}{ Arm-opx } & \multirow[t]{2}{*}{$\alpha$} & \multicolumn{2}{|c|}{ Opx-melt } & \multirow[t]{2}{*}{$\alpha$} \\
\hline & $\overline{\Delta^{49} \mathrm{Ti}}$ & $95 \%$ c.i & & $\overline{\Delta^{49} \mathrm{Ti}}$ & $95 \%$ c.i & & $\overline{\Delta^{49} \mathrm{Ti}}$ & $\overline{95 \% \text { c.i }}$ & \\
\hline Air & -0.092 & \pm 0.028 & 0.99991 & -0.089 & \pm 0.027 & 0.99991 & -0.002 & \pm 0.017 & 1.00000 \\
\hline FMQ-0.5 & -0.137 & \pm 0.030 & 0.99986 & -0.108 & \pm 0.033 & 0.99989 & -0.029 & \pm 0.030 & 0.99997 \\
\hline FMQ-2 & -0.150 & \pm 0.028 & 0.99985 & -0.173 & \pm 0.010 & 0.99983 & +0.023 & \pm 0.027 & 1.00002 \\
\hline IW-0.1 & -0.158 & \pm 0.020 & 0.99984 & -0.210 & \pm 0.028 & 0.99979 & +0.053 & \pm 0.032 & 1.00005 \\
\hline IW-0.2 & -0.140 & \pm 0.037 & 0.99986 & -0.197 & \pm 0.036 & 0.99980 & +0.058 & \pm 0.046 & 1.00006 \\
\hline IW-1 & -0.200 & \pm 0.033 & 0.99980 & -0.250 & \pm 0.049 & 0.99975 & +0.050 & \pm 0.025 & 1.00005 \\
\hline
\end{tabular}


Table 4 Fitting parameters derived from $\Delta^{49} \mathrm{Ti}_{\mathrm{A}-\mathrm{B}}$ (in \%o) of experimental samples

\begin{tabular}{lllll}
\hline$\Delta^{49} \sum \mathrm{Ti}_{\mathrm{A}-\mathrm{B}}$ & $\Delta^{49} \mathrm{Ti}^{3+}{ }_{\mathrm{A}-\mathrm{B}}$ & $\Delta^{49} \mathrm{Ti}^{4+}{ }_{\mathrm{A}-\mathrm{B}}$ & $\mathrm{K}^{\prime-1}$ & $\chi_{\nu}{ }^{2}$ \\
\hline$\Delta^{49} \mathrm{Ti}_{\text {opx-melt }}$ & +0.122 & -0.008 & 0.04 & 2.4 \\
$\Delta^{49} \mathrm{Ti}_{\text {arm-melt }}$ & -0.240 & -0.081 & 0.08 & 1.1 \\
$\Delta^{49} \mathrm{Ti}_{\text {arm-opx }}$ & -0.58 & -0.080 & 0.02 & 1.4 \\
\hline
\end{tabular}

experiments that are within 2 s.d. from our synthetic glass reference material have worked well and our general experimental setup is successful. Furthermore, since our mass balance varies within 2 s.d. of our synthetic glass reference material to positive and negative values, Ti-poor phases like orthopyroxene, and to a lesser extent glass, are most likely uncontaminated with isotopically light armalcolite as this would result in clear shifts in their Ti isotope composition to lighter values.

\section{Discussion}

\section{Ti isotope composition of mineral separates}

Terrestrial magmatic samples show a large range of $\delta^{49} \mathrm{Ti}$ between $-0.05-+2.32 \%$. These values are positively correlated with the $\mathrm{SiO}_{2}$ content of the rock (Millet et al. 2016; Deng et al. 2019; Hoare et al. 2020), which was interpreted to be the result of $\mathrm{Ti}$ oxide crystallization controlling the $\mathrm{Ti}$ budget with increasing magmatic differentiation. In a recent study, Zhao et al. (2020) analysed 60 magmatic samples from different tectonic settings and discovered that those saturated with a Fe-Ti oxide phase show a large range of $\delta^{49} \mathrm{Ti}$ values, from 0.005 to $1.914 \%$, positively correlated with $\mathrm{SiO}_{2}$ and negatively correlated with $\mathrm{MgO}$ sample content. The same study did not report any dependence of $\delta^{49} \mathrm{Ti}$ on either $\mathrm{MgO}$ or $\mathrm{SiO}_{2}$ content for rocks that did not have an Fe-Ti oxide phase, which corroborates and expands upon the interpretation and dataset of former studies (see Millet et al. 2016; Greber et al. 2017a, b; Deng et al. 2018, 2019; Johnson et al. 2019; Kommescher et al. 2020). Fractional crystallization of Ti oxides was also shown to be a key factor for Ti stable isotope fractionation present in lunar basalts (Millet et al. 2016; Kommescher et al. 2020). Since the $\delta^{49} \mathrm{Ti}$ of low-Ti basalts $(+0.01 \pm 0.047 \%$; Millet et al. 2016; Kommescher et al. 2020) broadly resembles that of the BSE $\left(\delta^{49} \mathrm{Ti}=+0.005 \pm 0.005 \%\right.$, Millet et al. 2016), whereas high-Ti basalts show a wider range of $\delta^{49} \mathrm{Ti}$ (between +0.009 and $+0.115 \%$; Millet et al. 2016; Kommescher et al. 2020), this difference between the different types of mare basalt suites has been interpreted to be the result of the fractional crystallization of ilmenite/armalcolite, as well as the partial melting of an IBC-component (Kommescher et al.
2020). However, most of these studies used whole rock bulk samples for their analyses. So far only a few studies investigated mineral separates (Johnson et al. 2019; Mandl 2019; He et al. 2020), which is, however, fundamental to understand mechanisms of Ti stable isotope fractionation during magmatic processes. Johnson et al. (2019) measured the Ti isotope compositions of mineral separates and the corresponding bulk rock from Kilauea Iki lava lake. Titanium oxides from that study (mostly ilmenite) display slightly lighter to overlapping $\delta^{49} \mathrm{Ti}$ (between $-0.03 \pm 0.02$ $\% o$ and $+0.06 \pm 0.03 \%$ ) compared to the whole rock (between $0.00 \pm 0.04 \%$ and $+0.05 \pm 0.03 \%$ ). Silicate mineral separates from the same samples showed higher $\delta^{49} \mathrm{Ti}$ (between $+0.07 \pm 0.03 \%$ and $+0.28 \pm 0.02 \%$ ) compared to the bulk rock. He et al. (2020) recently measured the Ti isotope compositions of mineral separates from the Qinghu monzonite. Ilmenite $\left({ }^{49} \mathrm{Ti}=+0.121 \pm 0.038\right.$ $\%$ o) and titanite $\left(8^{49} \mathrm{Ti}=+0.146 \pm 0.008 \%\right.$ ) showed a lighter $\mathrm{Ti}$ isotope composition compared to the whole rock $\left(\delta^{49} \mathrm{Ti}=+0.309 \pm 0.020 \%\right.$ ), whereas silicates like $\mathrm{K}$-feldspar and plagioclase were isotopically heavier $\left(\delta^{49} \mathrm{Ti}=+0.529 \pm 0.042 \% ; ;+0.613 \pm 0.064 \%\right.$ \% $)$ Only one study so far examined the Ti isotope fractionation of mineral separates from lunar basalt samples (Mandl 2019). Since all of their samples contained ilmenite, a clear Ti stable isotope fractionation between mineral separates and the host rock was observed (e.g., sample 12005 lowTi ilmenite basalt: $\delta^{49} \mathrm{Ti}=-0.008 \pm 0.011 \%$ and ilmenite: $\delta^{49} \mathrm{Ti}=-0.022 \pm 0.007 \%$; recalculated to OL-Ti from Mandl 2019). Likewise, our experimental armalcolites are isotopically lighter than coexisting melt and orthopyroxene, which is in line with previous results from natural samples (Millet et al. 2016; Johnson et al. 2019; Mandl 2019; He et al. 2020; Kommescher et al. 2020), unsurprisingly confirming the key role that Ti oxides play in determining the Ti stable isotope composition of magmatic samples during their differentiation and petrogenesis. Furthermore, orthopyroxene is the only silicate in our samples that systematically shows higher $\delta^{49} \mathrm{Ti}$ than coexisting melt in agreement with previous studies (Johnson et al. 2019; He et al. 2020). We note, however, that while the $\delta^{49} \mathrm{Ti}$ values of armalcolite, and to a lesser extent glass, are likely less vulnerable to contamination during handpicking because of their higher $\mathrm{TiO}_{2}$ contents (ca. $80 \mathrm{wt} . \%$ and $15 \mathrm{wt} . \% \mathrm{TiO}_{2}$, respectively), the $\delta^{49} \mathrm{Ti}$ of orthopyroxene is highly susceptible to crosscontamination because of its low $\mathrm{TiO}_{2}$ content (ca. 1 wt.\%). This is the most likely explanation for some of the lower than expected $\delta^{49} \mathrm{Ti}$ values for orthopyroxene in our dataset (i.e., at FMQ-0.5), as even a slight contamination by armalcolite will shift the $\delta^{49} \mathrm{Ti}$ to lower values. Nevertheless, since orthopyroxene contains only $\sim 1 \mathrm{wt} . \% \mathrm{TiO}_{2}$, it is expected to have only a negligible effect on the Ti stable isotope fractionation in natural magmatic systems. 


\section{How do redox conditions affect the Ti isotope fractionation $\Delta{ }^{49} \mathrm{Ti}_{\mathrm{A}-\mathrm{B}}$ between two phases in equilibrium?}

In most studies dealing with Ti stable isotope fractionation in magmatic systems, Ti has been exclusively tetravalent, and the influence of $f \mathrm{O}_{2}$ on the high-temperature stable isotope fractionation of $\mathrm{Ti}$ has not been considered beyond its role on the stability of Ti-bearing oxide phases (Millet et al. 2016; Deng et al. 2019; Johnson et al. 2019; He et al. 2020; Kommescher et al. 2020). Nevertheless, the role of oxygen fugacity and of varying redox conditions on Ti stable isotope fractionation needs to be addressed, especially when considering the more reducing conditions operating during lunar basalt petrogenesis (e.g., Kommescher et al. 2020), where $\mathrm{Ti}^{3+}$ is known to be stable in addition to $\mathrm{Ti}^{4+}$ (Simon and Sutton 2018; Leitzke et al. 2018).

There are several studies dealing with the oxidation state of $\mathrm{Ti}$ in pyroxenes, $\mathrm{Ti}$ oxides and glasses in lunar environments (Lindsley et al. 1974; Kesson and Lindsley 1975; Stanin and Taylor 1980; Simon et al. 2014; Simon and Sutton 2017, 2018; Leitzke et al. 2018). High-pressure experiments showed that armalcolites near metal saturation $(\sim \mathrm{IW})$ can incorporate a significant $\mathrm{M}^{3+}{ }_{2} \mathrm{TiO}_{5}$ component (Lindsley et al. 1974; Kesson and Lindsley 1975), and thus a significant amount of a trivalent cation. This was supported by Wechsler et al. (1977) who indicated that most lunar armalcolites contained between 4 and $11 \mathrm{~mol} \%$ of a $\mathrm{M}^{3+}{ }_{2} \mathrm{TiO}_{5}$ component in a solid solution. Stanin and Taylor (1980) conducted dynamic crystallization experiments and detected increasing $\mathrm{Ti}^{3+}$ contents in armalcolite $(<1-15 \%$ of the total Ti fraction) with decreasing $f \mathrm{O}_{2}$ (up to IW-1.2). A more recent study by Leitzke et al. (2018) performed experiments in a gas mixing furnace using the same starting composition as in our study. The Ti valence and its spatial coordination number were determined in their experimental run products via K-edge XANES spectroscopy (Leitzke et al. 2018). Armalcolites produced in the experiments by Leitzke et al. (2018) showed a strong $f \mathrm{O}_{2}$ related trend of $\mathrm{Ti}$ valence in armalcolite from $\sim 4$ (air) to $\sim 3.7$ (IW-1.7) with a constant VI-fold coordination number. Pyroxenes, in particular, showed that they can contain a mixture between IVand VI-fold coordinated $\mathrm{Ti}$, with as much as $82 \%$ (45\% on average) in the IV-fold site, and have an average Ti valence of 3.75 (or ca. $25 \mathrm{~mol} . \% \mathrm{Ti}^{3+}$ ) at $f \mathrm{O}_{2}$ relevant to lunar magmatism (Leitzke et al. 2018). These results are consistent with recent XANES measurements carried out by Simon and Sutton $(2017,2018)$ in natural lunar minerals.

Leitzke et al. (2018) also carried out ab initio modelling based on density-functional theory (DFT) of mass dependent Ti equilibrium isotope fractionation. They assumed different oxidation states of $\mathrm{Ti}\left({ }^{3+} /^{4+}\right)$ and coordination environments (IV-/VI-fold coordination) for clinopyroxene and the $\mathrm{Mg}$-rich endmember of the armalcolite-karrooite solid solution series $\left(\mathrm{MgTi}_{2} \mathrm{O}_{5}\right)$. The largest fractionation factor $(\beta)$ was observed for the incorporation of $\mathrm{Ti}^{4+}$ into the tetrahedral Si site of clinopyroxene, whereas the lowest $\beta$ value was predicted for both the incorporation of $\mathrm{Ti}^{3+}$ into the octahedral $\mathrm{Mg}$ site of clinopyroxene, and $\mathrm{Ti}$ in armalcolite (see Fig. 7 in Leitzke et al. 2018). More recently, Wang et al. (2020) reached similar conclusions with their own DFT ab initio modelling. Judging from the XANES data reported by Leitzke et al. (2018), pyroxene in our experiments should contain fewer than $25 \% \mathrm{Ti}^{3+}$ relative to total $\mathrm{Ti}$ in VI-fold coordination, while on average a little less than half $(45 \%)$ of its $\mathrm{Ti}^{4+}$ is expected to be present in IV-fold coordination at ca. IW-1. Based on the ab initio modelling by Leitzke et al. (2018), the pyroxene in our experiments is then expected to show higher $\delta^{49} \mathrm{Ti}$ values relative to armalcolite at $f \mathrm{O}_{2}$ relevant to lunar magmatism (i.e., a positive $\Delta^{49} \mathrm{Ti}_{\text {opx-arm }}$ ). This expectation, is reflected by our own dataset, where the Ti isotope fractionation for armacolite-orthopyroxene equilibria predicted by the Leitzke et al. model ( $\Delta^{49} \mathrm{Ti}_{\text {opx-arm }} \sim+0.3 \%$ ) is very close to what was determined for our experiments carried out IW-1 $\left(\Delta^{49} \mathrm{Ti}_{\text {opx-arm }} \sim+0.25 \%\right.$ o).

There are, however, apparent inconsistencies between our dataset and the ab initio modelling by Leitzke et al. (2018) and later by Wang et al. (2020). For example, both Leitzke et al. (2018) and Wang et al. (2020) have argued that $\mathrm{Ti}^{3+}$ in orthopyroxene substitutes into the VI-fold M1 site of this mineral, so it is possible that the spatial coordination of $\mathrm{Ti}$ changed slightly in orthopyroxene at lower $f \mathrm{O}_{2}$ to favour VI-fold coordination. This may account for the slightly higher $\Delta^{49} \mathrm{Ti}_{\text {opx-melt }}$ seen in our more reduced experiments compared to those carried out in air, where all $\mathrm{Ti}$ is tetravalent. Indeed, the sigmoidal relationship shown between $\Delta \Delta^{49} \mathrm{Ti}_{\text {opx-melt }}$ and $f \mathrm{O}_{2}$ is reminiscent of a similar relationship seen between the partitioning of Ti between pyroxene and melt and $f \mathrm{O}_{2}$ (Mallmann and O'Neill 2009). In that case the $\mathrm{D}_{\mathrm{Ti}}{ }^{\text {Opx/melt }}$ was shown to increase with decreasing $f \mathrm{O}_{2}$ due to an increasing proportion of $\mathrm{Ti}^{3+}$. It should be noted, however, that ab initio modelling indicates the substitution of $\mathrm{Ti}^{3+}$ in VI-fold coordination in orthopyroxene (Wang et al. 2020), which should result in lighter Ti isotope compositions in orthopyroxene due to the longer $\mathrm{Ti}^{3+}-\mathrm{O}$ bond lengths and lower force constants compared to $\mathrm{Ti}^{4+}-\mathrm{O}$ bonds. This expectation is not confirmed by our experimental results, as $\Delta^{49} \mathrm{Ti}_{\text {arm-opx }}$ are larger at lower $f \mathrm{O}_{2}$, possibly because the modelling of Wang et al. (2020) did not consider the presence of multiple simultaneous equilibria as we did in our experiments. Furthermore, Leitzke et al. (2018) did not determine how $\mathrm{Ti}^{4+}$ is distributed between the tetrahedral and octahedral sites in pyroxene under more oxidizing conditions, so a direct comparison with experiments carried out at IW-1 is not possible. Given the limited constraints, 
at present, we can only speculate that under more reducing conditions $\mathrm{Ti}^{4+}$ is perhaps pushed from VI-fold into IVfold coordination, because $\mathrm{Ti}^{3+}$ is exclusively sited in the octahedral $\mathrm{Mg}$ site in VI-fold coordination. The net effect of this process could presumably lead to a higher overall proportion of $\mathrm{Ti}-\mathrm{O}$ bonds in $\mathrm{IV}$-fold coordination relative to VI-fold coordination and hence to overall higher $\beta$ values at lower $\mathrm{fO}_{2}$.

Nevertheless, our results confirm that changing $\mathrm{fO}_{2}$ leads to the development of isotopically resolvable differences of $\delta^{49} \mathrm{Ti}$ between armalcolite, orthopyroxene and melt, which is probably due to their different coordination environments in conjunction with the oxidation state of $\mathrm{Ti}$ in the different phases.

However, given that our results show that $\mathrm{fO}_{2}$ clearly impacts on the value of $\Delta^{49} \mathrm{Ti}_{\mathrm{A}-\mathrm{B}}$, it is necessary to consider the effect of this parameter for more reducing environments like those associated with lunar magmatism. We, therefore, fitted our $\Delta^{49} \mathrm{Ti}_{\mathrm{A}-\mathrm{B}}$ data for the different phase equilibria (i.e., armalcolite-melt, orthopyroxene-melt and armalcolite-orthopyroxene) obtained at $1533 \mathrm{~K}$ to a logistical function based on the redox change of $\mathrm{Ti}$ as a function of $\mathrm{fO}_{2}$ :

$\mathrm{TiO}_{x / 2}+z / 4 \mathrm{O}_{2}=\mathrm{TiO}_{(x+z) / 2}$

and,

$\Delta^{49} \sum \mathrm{Ti}_{\mathrm{A}-\mathrm{B}}=\frac{\Delta^{49} \mathrm{Ti}_{\mathrm{A}-\mathrm{B}}^{(x+z)}+\Delta^{49} \mathrm{Ti}_{\mathrm{A}-\mathrm{B}}^{x} \times K^{\prime-1} \times \mathrm{e}^{\log f \mathrm{O}_{2}^{-\frac{z}{4}}}}{1+K^{\prime-1} \times \mathrm{e}^{\log f \mathrm{O}_{2}^{-\frac{z}{4}}}}$

where $x$ is the valence of the reduced Ti redox species, $z$ the number of electrons exchanged between both sides of reaction (2), $\Delta^{49} \mathrm{Ti}^{x+z}{ }_{\mathrm{A}-\mathrm{B}}$ and $\Delta^{49} \mathrm{Ti}^{x}{ }_{\mathrm{A}-\mathrm{B}}$ are the $\mathrm{Ti}$ isotope fractionation of fictive oxidized and reduced end-members, and $\mathrm{K}$ the equilibrium constant related to reaction (2). Because we know the oxidation state of $\mathrm{Ti}$ in both sides of reaction (2) - i.e., $\mathrm{Ti}^{3+}$ and $\mathrm{Ti}^{4+}$ - the number of electrons exchanged ( $z$ ) is one, and Eq. (3) can be simplified to:

$\Delta^{49} \sum \mathrm{Ti}_{\mathrm{A}-\mathrm{B}}=\frac{\Delta^{49} \mathrm{Ti}_{\mathrm{A}-\mathrm{B}}^{4+}+\Delta^{49} \mathrm{Ti}_{\mathrm{A}-\mathrm{B}}^{3+} \times K^{\prime-1} \times \mathrm{e}^{\log f O_{2}-\frac{1}{4}}}{1+K^{\prime-1} \times \mathrm{e}^{\log f O_{2}-\frac{1}{4}}}$

From Eq. (4) it is clear that $\Delta^{49} \mathrm{Ti}_{\mathrm{A}-\mathrm{B}}$ will depend on $f \mathrm{O}_{2}$, $\Delta^{49} \mathrm{Ti}^{4+}{ }_{\mathrm{A}-\mathrm{B}}$, which is known from the most oxidized experiments carried out in air, where all $\mathrm{Ti}$ is tetravalent, and $\Delta^{49} \mathrm{Ti}^{3+}{ }_{\mathrm{A}-\mathrm{B}}$, which represents a case, where all $\mathrm{Ti}$ is trivalent, and $\mathrm{K}$ '. The $\Delta^{49} \mathrm{Ti}_{\mathrm{A}-\mathrm{B}}$ values for the different phase equilibria were fitted to Eq. (4) using least squares regression likewise to what was commonly done to relate the partitioning of redox-sensitive elements like Re, V or Mo (Mallmann and
O'Neill 2007, 2009; Leitzke et al. 2017) to $\mathrm{fO}_{2}$, the results of which are shown in Table 4 and Fig. 5.

It should be pointed out, however, since we know that around IW-1.7 the mean Ti valence is 3.69 (Leitzke et al. 2018), our reduced experiment at IW-1 does not represent the real end member, where only trivalent Ti would be present. Therefore, our more reduced experiments are located at the slope of the fitted curve and not at the plateau on the more reduced end of the plot (Fig. 5). The reduced plateau at around IW-12 is supported by the known stability of tistarite $\left(\mathrm{Ti}^{3+}{ }_{2} \mathrm{O}_{3}\right)$ with very reducing conditions near IW-13 (Barin 1995). However, the more oxidized plateau is well defined by our oxidized experiments carried out in air that contain only tetravalent Ti (Leitzke et al. 2018). Our data indicates that the $\Delta^{49} \mathrm{Ti}_{\mathrm{A}-\mathrm{B}}$ has a clear dependence on $f \mathrm{O}_{2}$, namely larger $\mathrm{Ti}$ isotope fractionation at more reducing conditions. This isotope fractionation is probably connected to the change in oxidation state and spatial coordination (see Young et al. 2015; Sossi and O'Neill 2017) with decreasing $\mathrm{fO}_{2}$ described by Leitzke et al. (2018). However, Leitzke et al. did not identify a significant shift in the spatial coordination of $\mathrm{Ti}$ in armalcolite, orthopyroxene and silicate melt as a function of $\mathrm{fO}_{2}$, whereas the oxidation state of $\mathrm{Ti}$ in armalcolite, and to a lesser extent pyroxene, shows a clear redox dependence (Mallmann and O'Neill 2009; Leitzke et al. 2018). The oxidation state of $\mathrm{Ti}\left(f \mathrm{O}_{2}\right.$ dependent) thus appears to have a larger effect on Ti stable isotope fractionation than the coordination environment in the case of armalcolite, although we are hesitant to extent this conclusion to other phases, namely those we have not investigated in our study.

\section{Potential implications for the behaviour of stable Ti isotopes during lunar magmatism}

Several studies have investigated $\Delta^{49} \mathrm{Ti}_{\mathrm{A}-\mathrm{B}}$ in association with mineral-melt equilibria focussing on the effects of temperature and melt compositions, yet have not taken into account the influence of $f \mathrm{O}_{2}$. Millet et al. (2016) parameterized the temperature dependence of $\Delta^{49} \mathrm{Ti}_{\text {oxides-melt }}$ for their Agung volcanic samples with a range in $\mathrm{SiO}_{2}$ from 54-65 wt.\%, and obtained:

$\Delta^{49} \mathrm{Ti}_{\text {oxides-melt }}(\% o)=-0.23 \times 10^{6} / \mathrm{T}^{2}$

A similar temperature dependence of $\Delta^{49} \mathrm{Ti}_{\text {oxides-melt }}$ was determined by Deng et al. (2019) who obtained $\Delta^{49} \mathrm{Ti}_{\text {oxides-melt }} \sim-0.1 \%$ at $\sim 1500 \mathrm{~K}$ and $\sim-0.5 \%$ o at $\sim 1150 \mathrm{~K}$, on a sample set of Hekla lavas with a wider $\mathrm{SiO}_{2}$ range from 46-72 wt.\%. They were also the first to notice that their fractionation factors were not only controlled by temperature since there was no linear correlation between $\delta^{49} \mathrm{Ti}$ and $1 / \mathrm{T}^{2}$. Johnson et al. (2019) derived a new 
parameterization that incorporated $\Delta^{49} \mathrm{Ti}_{\text {oxides-melt }}$ data from Deng et al. (2019) to account for the effect of $\mathrm{SiO}_{2}$ combined with temperature:

$$
\begin{aligned}
\Delta^{49} \mathrm{Ti}_{\text {melt-oxide }}(\% o)= & {[-0.5( \pm 0.1)+0.017} \\
& \left.( \pm 0.002)\left(\mathrm{SiO}_{2}\right)\right] \times 10^{6} / \mathrm{T}^{2}
\end{aligned}
$$

More recently, Hoare et al. (2020) argued that while temperature certainly affects $\mathrm{Ti}$ stable isotope fractionation, its effect is relatively minor when compared to different oxide-melt equilibria. Specifically, Hoare et al. (2020), pointed out that the $\delta^{49} \mathrm{Ti}$ of natural magmatic samples varies (1) non-linearly with temperature for a given magmatic suite, and (2) its range is larger than expected from the temperature dependence alone. Instead, most of the variability seen in $8^{49} \mathrm{Ti}$ seems to depend on melt composition, namely the slope of the relationship between $\mathrm{FeO} /$ $\mathrm{TiO}_{2}$ and the $\mathrm{SiO}_{2}$ content of a magmatic sequence $[d(\mathrm{FeO} /$ $\left.\left.\mathrm{TiO}_{2}\right) / d \mathrm{SiO}_{2}\right]$, and the stoichiometry of any Ti-bearing oxides that crystallize throughout magmatic differentiation. Hoare et al. (2020) obtained the following relationship between the bulk solid-melt Ti isotope fractionation $\left(\alpha_{\text {solid-melt }}\right)$ and $d\left(\mathrm{FeO} / \mathrm{TiO}_{2}\right) / d \mathrm{SiO}_{2}$ for $-0.75<d(\mathrm{FeO} /$ $\left.\mathrm{TiO}_{2}\right) / d \mathrm{SiO}_{2}<+1.6$ :

$$
\begin{aligned}
\alpha_{\text {(solid-melt) }}= & -3.1 \times 10^{-4}\left( \pm 5 \times 10^{-5}\right) \\
& \times \frac{d\left(\frac{\mathrm{FeO}}{\mathrm{TiO}_{2}}\right)}{d \mathrm{SiO}_{2}}+0.99976\left( \pm 3 \times 10^{-5}\right)
\end{aligned}
$$

From Eq. (7), because lunar mare basalts have high $d\left(\mathrm{FeO} / \mathrm{TiO}_{2}\right) / d \mathrm{SiO}_{2}$ melts, the fractional crystallization of $\mathrm{Fe}-\mathrm{Ti}$ oxide phases like ilmenite and armalcolite is expected to produce significant Ti stable isotope fractionation, which is also observed in lunar (Millet et al. 2016; Kommescher et al. 2020) and terrestrial (Zhao et al. 2020) samples and supported by our experimental results. This is exemplified by the heavier $\mathrm{Ti}$ isotope composition of KREEP-rich lunar samples $\left(\delta^{49} \mathrm{Ti} \sim+0.3 \%\right.$ o $)$ when compared to primitive high-MgO mare basalts $\left(\delta^{49} \mathrm{Ti} \sim+0 \%\right.$ o (Millet et al. 2016; Greber et al. 2017a, b; Kommescher et al. 2020). Our isotopically light armalcolites confirm this behaviour especially since the armalcolite related fractionation is higher at lunar $f \mathrm{O}_{2}$ (i.e., IW-1) when compared to more oxidizing conditions. The observed change in $\delta^{49} \mathrm{Ti}$ as a function of $f \mathrm{O}_{2}$ is also expected for the crystallization of other Ti oxides, namely ilmenite (Millet et al. 2016; Kommescher et al. 2020).

Natural lunar basalts are sub-divided into high- and low-Ti basalts and are considered to have different origins. Low-Ti basalts are thought to result from the partial melting of mafic lunar mantle cumulates without the direct involvement of Ti-rich phases like ilmenite, which leads to overall average $\delta^{49} \mathrm{Ti}$ close to that of the bulk silicate Earth (BSE-Millet et al. 2016). On the other hand, highTi basalt petrogenesis has been linked to the partial melting of a mixture of lunar mantle cumulates, including the IBC (Longhi 1992; Sprung et al. 2013), which accounts for their higher $\delta^{49} \mathrm{Ti}$ values (Millet et al. 2016; Kommescher et al. 2020).

To model the behaviour of $\delta^{49} \mathrm{Ti}$ during mare basalt petrogenesis and fractional crystallization, we have combined trace element and Ti isotope data from natural lunar samples (Hf and Ta: Thiemens et al. 2019; $\delta^{49} \mathrm{Ti}$ : Kommescher et al. 2020) with experimental partitioning data for the trace elements sensitive to $\mathrm{Fe}-\mathrm{Ti}$ oxide crystallization (i.e., $\mathrm{Ti}$, $\mathrm{Ta}$ and Hf-van Kan Parker et al. 2011; Leitzke et al. 2016), and the experimentally determined $\Delta^{49} \mathrm{Ti}_{\mathrm{A}-\mathrm{B}}$ from this study (see Supplementary tables 8, 9 for model parameters). For armalcolite and clinopyroxene we have used our experimentally determined $\Delta^{49} \mathrm{Ti}_{\text {arm-melt }}$ and $\Delta^{49} \mathrm{Ti}_{\text {opx-melt }}$ values at IW-1 ( -0.2 and $+0.05 \%$, respectively), where we use our orthopyroxene data as an approximation for clinopyroxene. Titanium isotope fractionation data from ilmenite was taken from Mandl (2019) using the difference between their measured $\delta^{49} \mathrm{Ti}_{\text {ilmenite }}$ and $\delta^{49} \mathrm{Ti}_{\text {bulk }}$ as a proxy for $\Delta^{49} \mathrm{Ti}_{\text {ilmenite-melt }}$ $(-0.356 \%$ ) . Mineral-melt partition coefficients for Ti, Ta and Hf were taken from Leitzke et al. (2016) and van Westrenen et al. (2000).

The results of these models are shown in Fig. 6, where $\delta^{49} \mathrm{Ti}$ is plotted against a proxy for ilmenite, the Ta/Hf ratio, which is fractionated by both partial melting in the presence of ilmenite and armalcolite, or by their crystallization (Klemme et al. 2006; van Kan Parker et al. 2011; Leitzke et al. 2016). From the model results shown in Fig. 6, it is apparent that fractional crystallization forms a quasi-vertical array, where Ta/Hf slightly decreases while $\delta^{49} \mathrm{Ti}$ increases. Conversely, partial melting of a lunar mantle source containing variable proportions an $\mathrm{Fe}-\mathrm{Ti}$ oxide and orthopyroxene, forms arrays, where both $\delta^{49} \mathrm{Ti}$ and $\mathrm{Ta} / \mathrm{Hf}$ increase with increasing degree of melting.

The Apollo 11 and 17 high-Ti ilmenite basalts are thought to have originated from $250 \mathrm{~km}$ depth (Delano and Lindsley 1982). A parent magma similar to Apollo 17 sample 70017 is assumed for Apollo 11 and 17 high-Ti ilmenite basalts based on their high $\mathrm{MgO} / \mathrm{FeO}$ and $\mathrm{K} / \mathrm{Rb}$ ratios (Shi et al. 1975). Apollo 17 sample 75035 was reproduced by partial melting of a mantle source with $90 \%$ clinopyroxene and $10 \%$ olivine + ilmenite, whereas the samples 74255 and 74275 are thought to have originated from a mantle with $70 \%$ clinopyroxene and 30\% olivine + ilmenite (Shi et al. 1975). To evaluate how $\delta^{49} \mathrm{Ti}_{\text {melt }}$ changes during partial melting, we carried out aggregate partial melting models assuming different bulk Ti fractionation factors using both our experimental Ti isotope data for armalcolite and orthopyroxene, and the natural ilmenite Ti isotope data from Mandl (2019). 
Fig. 6 Modelling results of this study compared to natural lunar data (Figure symbols are identical to Kommescher et al. 2020). The high-Ti basalts can be reproduced best by partial melting of a source that contains $10 \%$ olivine + opaques, of which $25 \%$ is ilmenite, whereas the rest is armalcolite (purple line). The turquoise lines represent the partial melting of a source that either contains pure armalcolite or pure ilmenite. The $\delta^{49} \mathrm{Ti}$ of low-Ti basalts are reproduced by $60-75 \%$ fractional crystallization of Ti-oxides

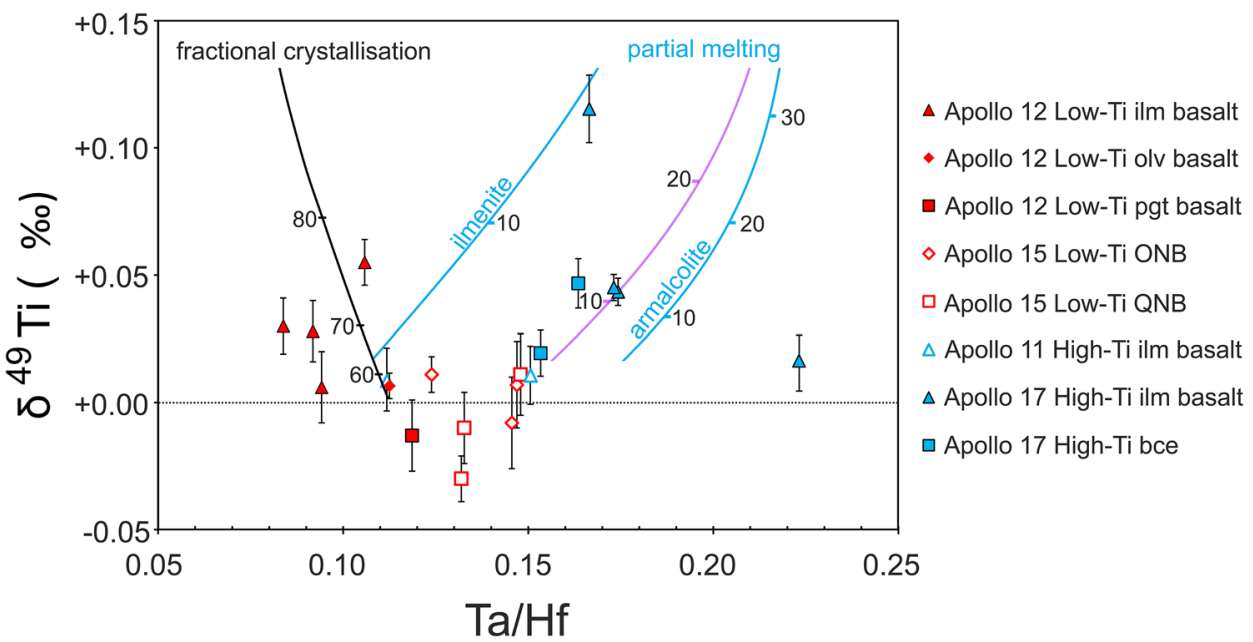

Following Kommescher et al. (2020) a lunar mantle source with $90 \%$ clinopyroxene and $10 \%$ olivine + ilmenite was assumed, as it is shown to reproduce the bulk of high-Ti mare basalt suites. In addition of modelling a source with just $10 \%$ ilmenite, we have also varied the ratio of ilmenite to armalcolite using the isotope fractionation data for both phases. Of course, armalcolite is not known to be stable at the higher pressures of mare basalt petrogenesis (6 to 15 kbar-Rai et al. 2019), and phases like ilmenite, rutile and ülvospinel likely dominate the IBC oxide assemblage under these conditions (Friel et al. 1977; Semytkivska 2010). However, we thought that using $\Delta^{49} \mathrm{Ti}_{\text {arm-melt }}$ from our experiment at IW-1 is likely a good proxy for a more realistic IBC oxide assemblage containing a mixture of ilmenite and other oxide phases with less $\mathrm{Ti}$, as it seems to have a slightly heavier $\mathrm{Ti}$ isotope composition $\left(\Delta^{49} \mathrm{Ti}_{\text {arm-melt }}\right.$ of $-0.2 \%$ ) compared to ilmenite $\left(\Delta^{49} \mathrm{Ti}_{\text {ilmenite-melt }}\right.$ of $-0.356 \%$ o $)$. The models show that $\sim 10 \%$ of partial melting of a lunar mantle source, where the ratio between armalcolite and ilmenite is 3:1 is able to reproduce the $\delta^{49} \mathrm{Ti}$ and $\mathrm{Ta} / \mathrm{Hf}$ values of high-Ti ilmenite basalt samples 74255 and 74275 . Taken at face value, the results of the fractional melting models indicate that the sources of these high-Ti basalts are unlikely to contain pure ilmenite in their oxide assemblage, and rather must contain a more complex oxide assemblage with higher overall $\Delta^{49} \mathrm{Ti}_{\mathrm{A}-\mathrm{B}}$ compared to a source with just ilmenite. These results highlight the potential of our experimental data in further discerning the nature of lunar mantle sources. However, it must be pointed out, that more Ti isotope data for a wider range of phase equilibria are required to robustly model the Ti isotope composition of lunar melts, and that the results of the current models should only be taken as rough estimates.

The low-Ti basalts are best represented by fractional crystallization of Ti-oxides after aggregate partial melting of a lunar mantle source with a composition close to the most primitive mare basalt sample in the sample suite low-Ti olivine basalt 12004 (as described in Kommescher et al. 2020). This liquid composition is produced from an assemblage that represents a late stage cumulate of the lunar magma ocean (90\% percent solidification with $20 \%$ clinopyroxene, $48 \%$ plagioclase and $32 \%$ pigeonite by Charlier et al. 2018) and subsequently used to model fractional crystallization of an ilmenite-bearing assemblage. Fractional crystallization was modelled with modal abundances derived for the low-Ti olivine basalt 12004 at $50 \mathrm{MPa}$ from Rhyolite MELTS for Excel (Gualda and Ghiorso 2015). We found that up until $50 \%$ fractional crystallization, $\delta^{49} \mathrm{Ti}$ of the melt becomes slightly negative until the first Ti-oxide (armalcolite) shows up at around $50 \%$ fractional crystallization. With the onset of Ti-oxide crystallization, $\delta^{49} \mathrm{Ti}$ of the melt becomes more and more positive until the presence of ilmenite ( $~ 95 \%$ fractional crystallization), where this trend is further accelerated. The high $\delta^{49} \mathrm{Ti}$ values of Apollo 12 low-Ti ilmenite basalts $12022,12051,12063$ and 12054 could be reproduced between 60 and $75 \%$ fractional crystallization with our experimentally determined $\Delta^{49} \mathrm{Ti}_{\text {arm-melt }}$ and $\Delta^{49} \mathrm{Ti}_{\text {opx-melt }}$ values at IW-1 ( -0.2 and $+0.05 \%$, respectively) and the $\Delta^{49} \mathrm{Ti}$ for ilmenite $(-0.356 \%$ ) from Mandl (2019). The expected relationship between $\delta^{49} \mathrm{Ti}$ and $\mathrm{Ta} / \mathrm{Hf}$ as a function of the degree of fractional crystallization is in broad agreement with natural observations.

\section{Concluding remarks}

Experimentally synthesized armalcolites have an isotopically light composition, whereas corresponding orthopyroxenes and glasses show an isotopically heavier composition. Our experimental results are, therefore, consistent with interpretations from previous whole rock Ti stable isotope measurements (Millet et al. 2016; Kommescher et al. 2020) as well as 
with previous mineral separate Ti stable isotope measurements (Johnson et al. 2019; Mandl 2019; He et al. 2020). $\Delta^{49} \mathrm{Ti}_{\mathrm{A}-\mathrm{B}}$ shows increasing fractionation with decreasing $f \mathrm{O}_{2}(\sim \mathrm{IW}-1)$. The relationship between $\Delta^{49} \mathrm{Ti}_{\mathrm{A}-\mathrm{B}}$ and $f \mathrm{O}_{2}$ appears to be directly related to the increasing abundance of $\mathrm{Ti}^{3+}$ at more reducing conditions, consistent with earlier studies that suggest a clear redox-dependency in armalcolite and pyroxene (see Leitzke et al. 2018). However, orthopyroxene-related $\Delta^{49} \mathrm{Ti}_{\mathrm{A}-\mathrm{B}}$ shows a smaller extent of redox-dependent fractionation, which is possibly due to the fact that orthopyroxene contains only minor amounts of $\mathrm{TiO}_{2}(\sim 1 \mathrm{wt} . \%)$. Nevertheless, the $\Delta^{49} \mathrm{Ti}_{\text {opx-melt }}$ is reminiscent of the redox-dependent $\mathrm{D}_{\mathrm{Ti}}{ }^{\text {Opx/melt }}$ by Mallmann and O'Neill (2009). The fractionation $\Delta^{49} \mathrm{Ti}_{\mathrm{A}-\mathrm{B}}$ determined in this study will be useful for modelling approaches of the lunar magma ocean, however, for future $\mathrm{Ti}$ isotope investigations, other Ti-bearing minerals (e.g., ulvöspinel, ilmenite and silicate minerals like clinopyroxene) should be targeted, especially since first order modelling results from Zhao et al. (2020) suggest that the magnetite-ulvöspinel solid solution influences the $\mathrm{Ti}$ isotope composition of a given system to an even larger degree than ilmenite and rutile. Titanium K-edge XANES measurements of pyroxenes synthetized at reducing conditions (IW-1.8) showed an average Ti valence of 3.75 and a mixture of IV- and VI-fold coordination numbers (Leitzke et al. 2018). Especially in high-Ti basalts, where a large fractionation of Ti isotopes has been identified (Kommescher et al. 2020), Ti in pyroxenes is more often octahedrally coordinated than in low-Ti basalts (Simon and Sutton 2018). Therefore, it would be interesting to further analyse clinopyroxenes from Ti-rich melt compositions, since they incorporate up to twice the amount of $\mathrm{Ti}$ when compared to orthopyroxene, and could potentially incorporate larger proportions of $\mathrm{Ti}$ in IV-fold coordination, which may lead to larger Ti isotope fractionation.

\footnotetext{
Acknowledgements The authors are grateful to Frank Wombacher and Carsten Münker for their help and access to the Isotope Geochemistry lab at the University of Cologne, and for extensive discussions that helped shape this work. We would also like to express our continued thanks to Marc-Alban Millet and Nicolas Greber for sharing the OL-Ti reference material. Furthermore, we want to thank Wim van Westrenen and Paolo Sossi for their constructive reviews that helped improve our manuscript and Hans Keppler for his expert editorial handling. ROCF is grateful for funding of a Heisenberg Professorship by the Deutsche Forschungsgemeinschaft (DFG grants FO 698/6-1 and FO 698/11-1). SK was partially funded through a UoC Advanced Post Doc grant within the Excellence Initiative to PS and acknowledges the UoC Graduate School of Geosciences for providing a fellowship (GSGS-2019X-07). FK acknowledges financial support by the German Research Foundation (DFG grant KU 3788/1-1) as part of the priority program 1833 "Building a Habitable Earth".
}

Author contributions ROCF, PS and FPL conceived the project. LR, ROCF and FPL designed the experimental protocol. LR, SK and FK developed the analytical protocol. LR wrote the manuscript and all authors contributed to the discussion and writing of the manuscript.
Funding Open Access funding enabled and organized by Projekt DEAL. LR was funded through the DFG grant FO 698/6-1. ROCF is grateful for funding of a Heisenberg Professorship by the German Research Foundation (DFG grant FO 698/11-1). SK was partially funded through a UoC Advanced Post Doc grant within the Excellence Initiative to PS and acknowledges the UoC Graduate School of Geosciences for providing a fellowship (GSGS-2019X-07). FK acknowledges financial support by the German Research Foundation (DFG grant KU 3788/1-1) as part of the priority program 1833 "Building a Habitable Earth".

Availability of data and material All authors have checked their data and brought it to field standards.

\section{Compliance with ethical standards}

Conflicts of interest The authors declare that they have no conflict of interest.

Open Access This article is licensed under a Creative Commons Attribution 4.0 International License, which permits use, sharing, adaptation, distribution and reproduction in any medium or format, as long as you give appropriate credit to the original author(s) and the source, provide a link to the Creative Commons licence, and indicate if changes were made. The images or other third party material in this article are included in the article's Creative Commons licence, unless indicated otherwise in a credit line to the material. If material is not included in the article's Creative Commons licence and your intended use is not permitted by statutory regulation or exceeds the permitted use, you will need to obtain permission directly from the copyright holder. To view a copy of this licence, visit http://creativecommons.org/licenses/by/4.0/.

\section{References}

Barin I (1995) Thermochemical data of pure substances, 3rd edn. VHC Verlagsgesellschaft mbH, Munich

Bast R, Scherer EE, Sprung P, Fischer-Gödde M, Stracke A, Mezger $K$ (2015) A rapid and efficient ion-exchange chromatography for $\mathrm{Lu}-\mathrm{Hf}, \mathrm{Sm}-\mathrm{Nd}$, and $\mathrm{Rb}-\mathrm{Sr}$ geochronology and the routine isotope analysis of sub-ng amounts of Hf by MC-ICP-MS. J Anal At Spectrom 30:2323-2333. https://doi.org/10.1039/C5JA00283D

Beard BL, Taylor LA, Scherer EE, Johnson CM, Snyder GA (1998) The source region and melting mineralogy of high-titanium and low-titanium lunar basalts deduced from Lu-Hf isotope data. Geochim Cosmochim Acta 62:525-544

Charlier B, Grove TL, Namur O, Holtz F (2018) Crystallization of the lunar magma ocean and the primordial mantle-crust differentiation of the Moon. Geochim et Cosmochim Acta 234:50-69

Compston W, Oversby VM (1969) Lead isotopic analysis using a double spike. J Geophys Res 74:4338-4348. https://doi.org/10.1029/ JB074i017p04338

Dauphas N, Roskosz M, Alp EE, Neuville DR, Hu MY, Sio CK, Tissot FLH, Zhao J, Tissandier L, Médard E, Cordier C (2014) Magma redox and structural controls on iron isotope variations in Earth's mantle and crust. Earth Planet Sci Lett 398:127-140. https://doi. org/10.1016/j.eps1.2014.04.033

Delano JW, Lindsley DH (1982) Chromium, Nickel, and Titanium Abundances in 74275 Olivines: More Evidence for a High-Pressure Origin of High-Titanium Mare Basalts. Lunar and Planetary Science XIII, p 160-161

Deng Z, Moynier F, Sossi PA, Chaussidon M (2018) Bridging the depleted MORB mantle and the continental crust using titanium 
isotopes. Geochem Perspect Lett 9:11-15. https://doi.org/10.7185/ geochemlet.1831

Deng Z, Chaussidon M, Savage P, Robert F, Pik R, Moynier F (2019) Titanium isotopes as a tracer for the plume or island arc affinity of felsic rocks. Proc Natl Acad Sci USA 116:1132. https://doi. org/10.1073/pnas.1809164116

Donaldson CH, Williams RJ, Lofgren G (1975) A sample holding technique for study of crystal growth in silicate melts. Am Min 60:324-326

Farges F, Brown GE, Rehr JJ (1996) Coordination chemistry of Ti(IV) in silicate glasses and melts: I. XAFS study of titanium coordination in oxide model compounds. Geochim Cosmochim Acta 60:3023-3038. https://doi.org/10.1016/0016-7037(96)00144-5

Fonseca ROC, Mallmann G, Sprung P, Sommer J, Heuser A, Speelmans IM, Blanchard H (2014) Redox controls on tungsten and uranium crystal/silicate melt partitioning and implications for the U/W and Th/W ratio of the lunar mantle. Earth Planet Sci Lett 404:1-13. https://doi.org/10.1016/j.eps1.2014.07.015

Friel JJ, Harker RI, Ulmer GC (1977) Armalcolite stability as a function of pressure and oxygen fugacity. Geochim Cosmochim Acta 41:403-410

Gale A, Dalton CA, Langmuir CH, Su Y, Schilling JG (2013) The mean composition of ocean ridge basalts. Geochem Geophys 14:489-518. https://doi.org/10.1029/2012GC004334

Greber ND, Dauphas N, Bekker A, Ptáček MP, Bindeman IN, Hofmann A (2017a) a) Titanium isotopic evidence for felsic crust and plate tectonics 3.5 billion years ago. Science 357:1271-1274. https:// doi.org/10.1126/science.aan8086

Greber ND, Dauphas N, Puchtel IS, Hofmann BA, Arndt NT (2017b) b) Titanium stable isotopic variations in chondrites, achondrites and lunar rocks. Geochim Cosmochim Acta 213:534-552. https ://doi.org/10.1016/j.gca.2017.06.033

Griffin WL, Gain SEM, Adams DT, Huang JX, Saunders M, Toledo V, Pearson NJ, O'Reilly SY (2016) First terrestrial occurrence of tistarite $\left(\mathrm{Ti}_{2} \mathrm{O}_{3}\right)$ : ultra-low oxygen fugacity in the upper mantle beneath Mount Carmel, Israel. Geology 44:815-818. https://doi. org/10.1130/G37910.1

Griffin WL, Gain SEM, Bindi L, Toledo V, Cámara F, Saunders M, O'Reilly SY (2018) Carmeltazite, $\mathrm{ZrAl}_{2} \mathrm{Ti}_{4} \mathrm{O}_{11}$, a new mineral trapped in corundum from volcanic rocks of Mt Carmel. Northern Israel Miner 8:601. https://doi.org/10.3390/min8120601

Gross J, Joy KH (2016) Evolution, lunar: from magma ocean to crust formation. In: Cudnik B (ed) Encyclopedia of lunar science. Springer International Publishing, Cham, pp 1-20. https://doi. org/10.1007/978-3-319-05546-6_39-1

Gualda GAR, Ghiorso MS (2015) MELTS_Excel: a microsoft Excelbased MELTS interface for research and teaching of magma properties and evolution. Geochem Geophys 16:315-324. https://doi. org/10.1002/2014GC005545

Haggerty SE (1973) Armalcolite and genetically associated opaque minerals in the lunar samples. Proc Lunar Planet Sci Conf 4:777-797

He X, Ma J, Wei G, Zhang L, Wang Z, Wang Q (2020) A new procedure for titanium separation in geological samples for ${ }^{49} \mathrm{Ti} /$ 47 Ti ratio measurement by MC-ICP-MS. J Anal At Spectrom 35:100-106. https://doi.org/10.1039/C9JA00316A

Hill E, Wood BJ, Blundy JD (2000) The effect of Ca-Tschermaks component on trace element partitioning between clinopyroxene and silicate melt. Lithos 53:203-215. https://doi.org/10.1016/S0024 $-4937(00) 00025-6$

Hoare L, Klaver M, Saji NS, Gillies J, Parkinson IJ, Lissenberg CJ, Millet M-A (2020) Melt chemistry and redox conditions control titanium isotope fractionation during magmatic differentiation. Geochim Cosmochim Acta 282:38-54. https://doi.org/10.1016/j. gca.2020.05.015
Johnson AC, Aarons SM, Dauphas N, Nie NX, Zeng H, Helz RT, Romaniello SJ, Anbar AD (2019) Titanium isotopic fractionation in Kilauea Iki lava lake driven by oxide crystallization. Geochim Cosmochim Acta 264:180-190. https://doi.org/10.1016/j. gca.2019.08.022

Kessel R, Schmidt MW, Ulmer P, Pettke T (2005) Trace element signature of subduction-zone fluids, melts and supercritical liquids at 120-180 km depth. Nature 437:724-727. https://doi.org/10.1038/ nature 03971

Kesson SE, Lindsley DH (1975) The effects of $\mathrm{Al}^{3+}, \mathrm{Cr}^{3+}$, and $\mathrm{Ti}^{3+}$ on the stability of armalcolite. Proc Lunar Sci Conf 6:911-920

Klemme S, Günther D, Hametner K, Prowatke S, Zack T (2006) The partitioning of trace elements between ilmenite, ülvospinel, armalcolite and silicate melts with implications for the early differentiation of the moon. Chem Geol 234:251-263

Kommescher S, Fonseca ROC, Kurzweil F, Thiemens MM, Münker C, Sprung P (2020) Unravelling lunar mantle source processes via the Ti isotope composition of lunar basalts. Geochem Perspect Lett 13:13-18. https://doi.org/10.7185/geochemlet.2007

Krawczynski MJ, Sutton SR, Grove TL, Newville M (2009) Titanium oxidation state and coordination in the lunar high-titanium glass source mantle. Lunar and Planetary Science Conference, 2164

Kurzweil F, Münker C, Tusch J, Schoenberg R (2018) Accurate stable tungsten isotope measurements of natural samples using a 180W-183W double-spike. Chemi Geol 476:407-417. https://doi. org/10.1016/j.chemgeo.2017.11.037

Leitzke FP, Fonseca ROC, Michely LT, Sprung P, Münker C, Heuser A, Blanchard $\mathrm{H}$ (2016) The effect of titanium on the partitioning behavior of high-field strength elements between silicates, oxides and lunar basaltic melts with applications to the origin of mare basalts. Chem Geol 440:219-238. https://doi.org/10.1016/j.chemgeo.2016.07.011

Leitzke FP, Fonseca ROC, Sprung P, Mallmann G, Lagos M, Michely LT, Münker C (2017) Redox dependent behaviour of molybdenum during magmatic processes in the terrestrial and lunar mantle: implications for the Mo/W of the bulk silicate Moon. Earth Planet Sci Lett 474:503-515. https://doi.org/10.1016/j.epsl.2017.07.009

Leitzke FP, Fonseca ROC, Göttlicher J, Steininger R, Jahn S, Prescher C, Lagos M (2018) Ti K-edge XANES study on the coordination number and oxidation state of Titanium in pyroxene, olivine, armalcolite, ilmenite, and silicate glass during mare basalt petrogenesis. Contrib Mineral Petrol 173:103. https://doi.org/10.1007/ s00410-018-1533-7

Lindsley DH, Kesson SE, Hartzman MJ, Cushman MK (1974) The stability of armalcolite - experimental studies in the system $\mathrm{MgO}$ Fe-Ti-O. Proc Lunar Sci Conf 5:521-534

Longhi J (1992) Experimental petrology and petrogenesis of mare volcanics. Geochim Cosmochim Acta 56:2235-2251. https://doi. org/10.1016/0016-7037(92)90186-M

Mallmann G, O'Neill HStC (2007) The effect of oxygen fugacity on the partitioning of Re between crystals and silicate melt during mantle melting. Geochim Cosmochim Acta 71:2837-2857. https ://doi.org/10.1016/j.gca.2007.03.028

Mallmann G, O'Neill HStC (2009) The crystal/melt partitioning of $\mathrm{V}$ during mantle melting as a function of oxygen fugacity compared with some other elements ( $\mathrm{Al}, \mathrm{P}, \mathrm{Ca}, \mathrm{Sc}, \mathrm{Ti}, \mathrm{Cr}, \mathrm{Fe}, \mathrm{Ga}, \mathrm{Y}$, $\mathrm{Zr}$ and Nb). J Petrol 50:1765-1794. https://doi.org/10.1093/petro logy/egp053

Mandl MB (2019) Titanium isotope fractionation on the Earth and Moon: Constraints on magmatic processes and Moon formation. Dissertation, ETH Zurich. https://doi.org/10.3929/ethz-b-00035 1171

Marvin UB, Walker D (1978) Implications of a titanium-rich glass clod at Oceanus Procellarum. Am Min 63:924-929

Millet M-A, Dauphas N (2014) Ultra-precise titanium stable isotope measurements by double-spike high resolution MC-ICP-MS. J Anal At Spectrom 29:1444. https://doi.org/10.1039/C4JA00096J 
Millet M-A, Dauphas N, Greber ND, Burton KW, Dale CW, Debret B, Macpherson CG, Nowell GM, Williams HM (2016) Titanium stable isotope investigation of magmatic processes on the Earth and Moon. Earth Planet Sci Lett 449:197-205. https://doi. org/10.1016/j.eps1.2016.05.039

Münker C, Weyer S, Scherer E, Mezger K (2001) Separation of high field strength elements ( $\mathrm{Nb}, \mathrm{Ta}, \mathrm{Zr}, \mathrm{Hf})$ and $\mathrm{Lu}$ from rock samples for MC-ICPMS measurements. Geochem Geophys. https://doi. org/10.1029/2001GC000183

Myers J, Eugster HP (1983) The system Fe-Si-O: oxygen buffer calibrations to 1,500K. Contrib Mineral Petrol 82:75-90. https://doi. org/10.1007/BF00371177

Neuville DR, Mysen BO (1996) Role of aluminium in the silicate network: in situ, high-temperature study of glasses and melts on the join $\mathrm{SiO} 2-\mathrm{NaAlO} 2$. Geochim Cosmochim Acta 60:1727-1737. https://doi.org/10.1016/0016-7037(96)00049-X

Palme H, O'Neill HStC (2014) Cosmochemical estimates of mantle composition. Treatise on geochemistry. Elsevier, Amsterdam, pp $1-39$

Poitrasson F, Cruz Vieira L, Seyler P, Pinheiro GMD, Mulholland DS, Bonnet M-P, Martinez J-M, Lima BA, Boaventura GR, Chmeleff J, Dantas EL, Guyot J-L, Mancini L, Pimentel MM, Santos RV, Sondag F, Vauchel P (2014) Iron isotope composition of the bulk waters and sediments from the Amazon River Basin. Chem Geol 377:1-11. https://doi.org/10.1016/j.chemgeo.2014.03.019

Prytulak J, Elliott T (2007) $\mathrm{TiO}_{2}$ enrichment in ocean island basalts. Earth Planet Sci Lett 263:388-403. https://doi.org/10.1016/j. eps1.2007.09.015

Rai N, Perrillat J-P, Mezouar M, Colin A, Petitgirard S, van Westrenen W (2019) In situ viscometry of primitive lunar magmas at high pressure and high temperature. Front Earth Sci 7:94. https://doi. org/10.3389/feart.2019.00094

Ringwood AE, Kesson SE (1976) A dynamic model for mare basalt petrogenesis. Proc Lunar Sci Conf 7:1697-1722

Rudge JF, Reynolds BC, Bourdon B (2009) The double spike toolbox. Chem Geol 265:420-431. https://doi.org/10.1016/j.chemg eo.2009.05.010

Schauble EA (2004) Applying stable isotope fractionation theory to new systems. Rev Mineral Geochem 55:65-111. https://doi. org/10.2138/gsrmg.55.1.65

Schoenberg R, Zink S, Staubwasser M, von Blanckenburg F (2008) The stable $\mathrm{Cr}$ isotope inventory of solid Earth reservoirs determined by double spike MC-ICP-MS. Chem Geol 249:294-306. https:// doi.org/10.1016/j.chemgeo.2008.01.009

Semytkivska N (2010) Picro-ilmenites: An experimental study in simple and complex systems to investigate $\mathrm{PT}-\mathrm{fO}_{2}-$ composition relations at high pressure Dissertation, ETH Zurich. https://doi. org/10.3929/ethz-a-006132710

Shearer CK, Hess PC, Wieczorek MA, Pritchard ME, Parmentier EM, Borg J, Elkins-Tanton LT, Neal CR, Antonenko I, Canup R, Halliday AN, Grove TL, Hager BH, Lee D-C, Wiechert U (2006) Thermal and magmatic evolution of the Moon. Rev Mineral Geochem 60:365-518. https://doi.org/10.2138/rmg.2006.60.4

Shi C-Y, Haskin LA, Wiesmann H, Bansal BM, Brannon JC (1975) On the origin of high-Ti mare basalts. Proc Lunar Sci Conf 6:1255-1285

Simon SB, Sutton SR (2017) Valence of Ti, V, and Cr in Apollo 14 aluminous basalts 14053 and 14072. Meteorit Planet Sci 52:20512066. https://doi.org/10.1111/maps. 12908

Simon SB, Sutton SR (2018) Valences of Ti, Cr, and V in Apollo 17 high-Ti and very low-Ti basalts and implications for their formation. Meteorit Planet Sci 53:2138-2154. https://doi.org/10.1111/ maps. 13123

Simon SB, Sutton SR, Grossman L (2014) Valence of Ti in Lunar Igneous Rocks: The First Direct Measurements. Lunar and Planetary Institute, TheWoodlands, Texas, p Abstract \#1063
Sossi PA, Moynier F (2017) Chemical and isotopic kinship of iron in the Earth and Moon deduced from the lunar Mg-Suite. Earth Planet Sci Lett 471:125-135. https://doi.org/10.1016/j. eps1.2017.04.029

Sossi PA, O'Neill HStC (2017) The effect of bonding environment on iron isotope fractionation between minerals at high temperature. Geochim Cosmochim Acta 196:121-143. https://doi. org/10.1016/j.gca.2016.09.017

Sprung P, Kleine T, Scherer EE (2013) Isotopic evidence for chondritic $\mathrm{Lu} / \mathrm{Hf}$ and Sm/Nd of the Moon. Earth Planet Sci Lett 380:77-87. https://doi.org/10.1016/j.eps1.2013.08.018

Stanin FT, Taylor LA (1980) Armalcolite: an oxygen fugacity sensor. lunar and planetary science conference, 1980. Proc Lunar Sci Conf 1:117-124

Thiemens MM, Sprung P, Fonseca ROC, Leitzke FP, Münker C (2019) Early Moon formation inferred from hafnium-tungsten systematics. Nat Geosci 12:696-700. https://doi.org/10.1038/s4156 1-019-0398-3

Tusch J, Sprung P, van de Löcht J, Hoffman JE, Boyd AJ, Rosing MT, Münker C (2019) Uniform 182W isotope compositions in Eoarchean rocks from the Isua region, SW Greenland: the role of early silicate differentiation and missing late veneer. Geochim Cosmochim Acta 257:284-310. https://doi.org/10.1016/j.gca.2019.05.012

van Kan PM, Mason PRD, van Westrenen W (2011) Experimental study of trace element partitioning between lunar orthopyroxene and anhydrous silicate melt: effects of lithium and iron. Chem Geol 285:1-14. https://doi.org/10.1016/j.chemgeo.2011.02.007

van Westrenen W, Blundy JD, Wood BJ (2000) Effect of $\mathrm{Fe}^{2+}$ on garnet-melt trace element partitioning: experiments in FCMAS and quantification of crystal-chemical controls in natural systems. Lithos 53:189-201. https://doi.org/10.1016/S0024 $-4937(00) 00024-4$

Wadhwa M (2008) Redox conditions on small bodies, the Moon and Mars. Rev Mineral Geochem 68:493-510. https://doi.org/10.2138/ rmg.2008.68.17

Wang W, Huang S, Huang F, Zhao X, Wu Z (2020) Equilibrium intermineral titanium isotope fractionation: implication for high-temperature titanium isotope geochemistry. Geochim Cosmochim Acta 269:540-553. https://doi.org/10.1016/j.gca.2019.11.008

Warren PH (1989) KREEP: major-element diversity, trace-element uniformity (almost). Workshop on Moon in Transition: Apollo 14, KREEP, and Evolved Lunar Rocks: 149-153

Warren PH (1985) The magma ocean concept and lunar evolution. Annu Rev Earth Planet Sci 13:201-240. https://doi.org/10.1146/ annurev.ea.13.050185.001221

Warren PH, Taylor GJ (2014) 2.9—-the Moon. In: Holland HD, Turekian KK (eds) Treatise on geochemistry (second edition). Elsevier, Oxford, pp 213-250

Wechsler BA (1977) Cation distribution and high-temperature crystal chemistry of armalcolite. Am Min 62:913-920

Young ED, Manning CE, Schauble EA, Shahar A, Macris CA, Lazar C, Jordan M (2015) High-temperature equilibrium isotope fractionation of non-traditional stable isotopes: experiments, theory, and applications. Chem Geol 395:176-195. https://doi.org/10.1016/j. chemgeo.2014.12.013

Zhao X, Tang S, Li J et al (2020) Titanium isotopic fractionation during magmatic differentiation. Contrib Mineral Petrol 175:67. https:// doi.org/10.1007/s00410-020-01704-1

Publisher's Note Springer Nature remains neutral with regard to jurisdictional claims in published maps and institutional affiliations. 